\title{
Influence of Additives on the Electrodeposition of Zinc from a Deep Eutectic Solvent
}

\author{
Hasan F. Alesary ${ }^{1,2}$, Salih Cihangir ${ }^{1}$, Andrew D. Ballantyne ${ }^{1}$, Robert C. Harris ${ }^{1}$, \\ David P. Weston ${ }^{3}$, Andrew P. Abbott ${ }^{1}$ and Karl S. Ryder * 1 \\ ${ }^{1}$ Materials Centre, Department of Chemistry, University of Leicester, Leicester, UK LE1 7RH \\ k.s.ryder@le.ac.uk \\ ${ }^{2}$ Department of Chemistry, College of Science, University of Karbala, Karbala, Iraq. \\ ${ }^{3}$ Department of Engineering, University of Leicester, Leicester, LE1 7RH, UK.
}

\begin{abstract}
The effects of nicotinic acid (NA), boric acid (BA) and benzoquinone (BQ) on the electrodeposition of $\mathrm{Zn}$ have been studied in a choline chloride $(\mathrm{ChCl})$ ethylene glycol (EG) based deep eutectic solvent (DES), (1ChCl:2EG), and for the first time a bright zinc coating has been achieved when NA was used.

In metal electroplating processes, small-molecule additives are often included in the plating bath to improve properties of coating such as brightness, roughness, thickness, hardness and resistance to corrosion. The effects of additives on the electrodeposition of $\mathrm{Zn}$ from aqueous solution have been extensively investigated. However, very few studies have considered the effects of additives on the electrodeposition of $\mathrm{Zn}$ from ionic liquids or deep eutectic solvents. The electrochemical properties of the plating liquid have been studied here using cyclic voltammetry, chronocoulometry, chronoamperometry and microgravimetry (EQCM). Redox peak currents decrease when additives were included in the $\mathrm{Zn}$ solution and total charge was also reduced in experiments where additives were present. The $\mathrm{Zn}$ deposition being in good agreement with an instantaneous growth mechanism without additives changed to one of a progressive growth mechanism when additives were included in the coating bath. The current efficiency of zinc deposition in the DES without additives was 95\%, which was reduced when additives were included. The resultant surface morphologies, thickness, topography, roughness and crystal structure of the $\mathrm{Zn}$ coating were revealed by scanning electron microscopy (SEM), atomic force microscopy (AFM) and X-ray diffraction (XRD), demonstrating that those additives serve as effective brighteners that can produce highly uniform and smooth zinc deposits.
\end{abstract}

\section{Key Words}

Electroplating, zinc, deep eutectic solvents, additives 


\section{Introduction}

The electrodeposition of metal from ionic liquids (ILs) and deep eutectic solvents (DES) is an area that has received intense study; ${ }^{1,2}$ however, relatively few studies have investigated the role of additives. 1,3 Zinc coatings are widely used in the field of corrosion-resistant coatings and energy storage. ${ }^{4,5,6}$, Traditional zinc electrodeposition is usually performed in cyanide baths, acidic sulphate baths and acid chloride zinc baths. 4,7,8 The clear problem with these electrolytes, however, is that they are all both corrosive and highly toxic; furthermore, they all have a significant negative impact on the environment. Consequently, there is considerable interest in alternative electrolytes for zinc deposition.

Around ten years ago, deep eutectic solvents (DESs) were suggested as alternatives to classical room temperature ionic liquids, ${ }^{9,10,11,12}$ as deep eutectic solvents, compared to ionic liquids, have excellent properties such as low cost, minimal toxicity, high metal solubility and are less sensitive to water. ${ }^{10,11,13,14,15,16}$ DES media are proposed for various electrochemical applications such as metal electrodeposition. ${ }^{17}$ Significant hydrogen evolution can result from the electrodeposition of metals from aqueous solutions. Hydrogen evolution, which is produced on the cathodic electrode surface, results in lowered current efficiency and often embrittlement. Given that hydrogen evolution and low current efficiency are clearly issues in the industrial plating of zinc, DESs could offer an attractive alternative for Zn plating that would allow these problems to be circumvented. ${ }^{18}$

In this research, the effect of organic additives on $\mathrm{Zn}$ electrodeposition from deep eutectic solvents was investigated at $80^{\circ} \mathrm{C}$. Different types of organic additives have been used in the electroplating of $\mathrm{Zn}$ from aqueous systems. It is extremely important to use these additives in the electrodeposition solvent due to their effect on the growth, morphology and structure of the resulting deposits. ${ }^{19}$ They are normally added to the plating bath to improve properties of the electrodeposit, such as grain size, brightness, internal stress, hardness and resistance to corrosion. 19,20,21 However, whilst additives might promote such desirable properties, the detailed role they play in the electrodeposition process is often not clearly understood, hence rapid development in the field is inevitably hampered by the empirical nature of the associated research. ${ }^{19}$ Researchers have suggested that additives can be adsorbed on the active side of the substrate and raise the activation 
polarization of single ions, or otherwise that some additives act as inhibitors, or the additives could be acting as complexing agents. ${ }^{19}$

Additives are normally high molecular weight polymeric organic compounds, such as polyethoxylated compounds, which are used to produce bright $\mathrm{Zn}$ deposits from acidic electrolytes. ${ }^{19}$ Alternatively, additives can be species that form colloidal suspensions, which are more effective than small ions or single molecules. Organic additives that have been used in $\mathrm{Zn}$ electroplating from aqueous solution include benzoic acid (BA), polyethylene glycols (PEGs), p-benzoquinone (BQ) and boric acid $\left(\mathrm{H}_{3} \mathrm{BO}_{3}\right) .{ }^{19,20}$ The influence of additives on $\mathrm{Zn}$ electrodeposition from ionic liquids has also been studied. Iwagishi studied the effects of ethylene glycol, 1,3-propanediol, 1,2-butanediol and 1,3butanediol on the electrodeposition of $\mathrm{Zn}$ from the Lewis base of liquid 1-ethyl-3methylimidazoliumbromide: $\mathrm{ZnCl}_{2},{ }^{22,23}$ demonstrating that the addition of each of these species enhanced the current efficiency of the process, obtaining a smooth $\mathrm{Zn}$ deposit in each case. Bright metal deposits were achieved from ILs when phenanthroline, acetonitrile, ethylenediaminetetraacetic acid (EDTA) and sodium acetylacetonate were added to the plating bath. ${ }^{24}$ Endres et al. ${ }^{25}$ showed that a brighter surface finish was produced for $\mathrm{Pd}$ and $\mathrm{Al}-\mathrm{Mn}$ alloys from the $\mathrm{AlCl}_{3}-1$-butyl-3-methylimidazolium-chloride IL when nicotinic acid was used as an additive. Recently, Liu et al. have studied zinc electrodeposition from ionic liquids. ${ }^{26}$ Chlorozincate ionic liquids were used for the deposition of $\mathrm{Zn} .{ }^{27}$ The electrochemical potential windows of ILs are unusually wide compared to those of aqueous electrolytes, therefore, ILs can be used in the electrodeposition of Zn.

Five years ago, Xingwu Guo et al. ${ }^{28}$ studied the effects of nicotinic acid on the electrodeposition of Ni from deep eutectic solvents. They found that nicotinic acid was able to produce a uniform smooth and bright Ni coating. Recently, we have studied the effects of nicotinic acid, methylnicotinate boric acid and 5,5-dimethylhydantoin on the electrodeposition of Ni from a choline chloride $(\mathrm{ChCl})$ ethylene glycol (EG) based DES. 29 This is a $1 \mathrm{ChCl}: 2 \mathrm{EG}$ stoichiometry and is available under the commercial name Ethaline. It was interesting to note that bright mirror Ni coatings were produced as a result of using these additives.

The aim of the current study was to understand the effect of small molecule additives on the electrodeposition of Zn coatings from a DES electrolyte. Within this general area, the specific objectives were $i$ ) to study the behaviour of a small set of additives currently 
used in aqueous electrolysis, $i$ ) determine the effect on electrochemical parameters of growth such current efficiency and nucleation / growth rate, iii) quantify the effect of additives on physical parameters of the film such as surface roughness, structure. Here we report the effects of three different additives (referred to as levellers and brighteners) on the electrodepistion of $\mathrm{Zn}$ from a deep eutectic solvent (Ethaline). The additives tested included nicotinic acid (NA), boric acid (BA) and $p$-benzoquinone (BQ). Properties of zinc coating were found to be improved compared to the corresponding system without additives, and for the first time a bright zinc coating has been achieved on a copper substrate. These additives were chosen as a sample of those small molecule species that are in common use as levellers and brighteners in our previous work (effect of nicotinic acid, methylnicotinate boric acid and 5,5-dimethylhydantoin on the electrodeposition of Ni from Ethaline). Cyclic voltammetry, chronocoulometry, chronoamperometry and the quartz crystal microbalance were used to elucidate aspects of the $\mathrm{Zn}$ ion reduction with these additives. The effect of those additives on morphology, thickness, roughness and crystal structure of the $\mathrm{Zn}$ coating were also investigated.

\section{Experimental}

Choline chloride, $\left[\mathrm{HOC}_{2} \mathrm{H}_{4} \mathrm{~N}\left(\mathrm{CH}_{3}\right)_{3} \mathrm{Cl}\right](\mathrm{ChCl})$ (Aldrich 99\%) was recrystallised from absolute ethanol, filtered and dried under vacuum. Ethylene glycol (EG) (Aldrich $+99 \%$ ), was used as received. Here, ethylene glycol (EG) is considered to be a hydrogen-bond donor. The deep eutectic mixture was prepared by continuous stirring of the two components at $60^{\circ} \mathrm{C}$ until a homogeneous, colourless liquid was formed. The zinc chloride, $\mathrm{ZnCl}_{2}$ (Aldrich $\geq 98 \%$ ), was used at a concentration of $0.4 \mathrm{M}$ and $0.6 \mathrm{M}$. the concentrations of additives used in the electrodeposition process were nicotinic acid (NA, $0.05 \mathrm{M})$ (Sigma $\geq 99.5 \%$ ), benzoquinone (BQ, $0.03 \mathrm{M}$ ) (Aldrich $98 \%$ ) and boric acid (BA, 0.2 M) (Analar 99.8\%) were all used as received.

Cyclic voltammetry, chronocoulometry and chronoamperometery were performed using an Autolab PGSTAT12 potentiostat controlled by the GPES2 software (version 4.9). The electrochemical cell consisted of three electrodes: a Pt disc (1 $\mathrm{mm}$ dia.) working electrode, a Pt flag counter electrode and an $\mathrm{Ag} / \mathrm{AgCl}$ reference electrode. Cyclic voltammograms were recorded using a potential window of 0.0 to $1.5 \mathrm{~V}$. In all experiments, the working electrode was polished between each experiment with $0.05 \mu \mathrm{m}$ 
$\gamma$-alumina paste, washed with deionised water and then with acetone. Voltammograms were carried out at the same temperature as the plating (typically $80^{\circ} \mathrm{C}$ ).

The data from the Quartz Crystal Microbalance (QCM) technique were recorded using a Hewlett-Packard 87512A transmission/ reflectance unit via a $50 \Omega$ coaxial cable, such that the centre of the recorded spectra was close to the resonant frequency, $f_{0}$, of the crystal (ca. $10 \mathrm{MHz}$ ). To improve temporal resolution, the network analyser data acquisition was controlled using a computer running the HP VEE software. This program is capable of recording admittance spectra every 2-3 s.

In this work, a $10 \mathrm{MHz}$ AT-cut polished (flat mirror) finish quartz crystal with a platinum film thickness of $900 \AA$, deposited in a keyhole shape on both sides with central disc active area of $0.23 \mathrm{~cm}^{2}$, was used (International Crystal Manufacturing Co., Oklahoma City, USA.). The crystal was placed in a Teflon cell such that one face of the crystal was exposed to the solution and one face was exposed to air. The three-electrode electrochemical cell was completed with a Pt flag counter electrode and an $\mathrm{Ag} / \mathrm{AgCl}$ reference electrode. The measurements were performed at $-1.25 \mathrm{~V}$ for $\mathrm{Zn}$ deposition at $80{ }^{\circ} \mathrm{C}$.

The electrodepositions were achieved on a $\mathrm{Cu}$ substrate from Ethaline containing $0.4 \mathrm{M}$ $\mathrm{ZnCl}_{2}$ in the presence and absence of additives. The cathode substrate was, firstly, etched with an aqueous $0.87 \mathrm{M}$ ammonium persulfate solution, $\left(\mathrm{NH}_{4}\right)_{2} \mathrm{~S}_{2} \mathrm{O}_{8}$ (Aldrich) and $0.2 \mathrm{M}$ $\mathrm{H}_{2} \mathrm{SO}_{4}$ (Fisher) solution, washed with water and then dried. The anode was Ti mesh, and the electrodepositions were performed at $80^{\circ} \mathrm{C}$ and a current density of $3.3 \mathrm{~mA} \mathrm{~cm}{ }^{-2}$ for $2 \mathrm{~h}$.

Scanning electron microscope (SEM) images were carried out using a Phillips XL30 ESEM instrument with an accelerator voltage of $20 \mathrm{keV}$, giving an average beam current of ca. $120 \mu \mathrm{A}$. Cross-section microstructure of the $\mathrm{Zn}$ coatings were mounted in a resin using a Struers LaboPress 3. The samples were then polished first with 240 grit silicon carbide paper to make them flat, then with diamond abrasives of successively $9 \mu \mathrm{m}$ and $3 \mu \mathrm{m}$ size and finally with a $0.05 \mu \mathrm{m}$ colloidal silica. Atomic force micrographs were acquired using a Digital Instruments Nanoscope IV Dimension 300 (Veeco) atomic force microscope with a $100 \mathrm{~mm}$ scanning head was used in both contact and tapping (resonant) modes. The controlling software was Nanoscope version 6.13. Images were acquired in air. Powder X-ray diffraction was performed using a Phillips model PW 1730 X-ray 
generator, with a PW 1716 diffractometer and PW 1050/25 detector. The X-ray tube was a long fine-focus $\mathrm{Cu}$ anode with $\mathrm{Ni} \mathrm{K} \alpha$-filtered radiation of wave. It was typical operated at $40 \mathrm{kV}, 30 \mathrm{~mA}$, and scanned between 15 and $110^{\circ} 2 \theta$ with a step size of $0.02^{\circ} 2 \theta$. Angle calibration was carried out using a synthetic Si sintered standard.

\section{Results and discussion}

\section{Effect of temperature on the voltammetric behaviour of $\mathrm{Zn}$ (II)}

Cyclic voltammetry of $\mathrm{ZnCl}_{2}$ in Ethaline has been studied at room temperature and at elevated temperature $\left(80^{\circ} \mathrm{C}\right)$. Fig. 1 shows a comparison of the cyclic voltammetry of Ethaline containing $0.4 \mathrm{M} \mathrm{ZnCl}_{2}$ at room temperature and at $80{ }^{\circ} \mathrm{C}$; both experiments were recorded at a scan rate of $30 \mathrm{mV} \mathrm{s}^{-1}$. The cyclic voltammograms of $\mathrm{ZnCl}_{2}$ recorded at $80{ }^{\circ} \mathrm{C}$ differed significantly from those recorded at room temperature, showing a dramatic increase in the $\mathrm{Zn}$ deposition and dissolution current peaks when performed at $80{ }^{\circ} \mathrm{C}$. This was anticipated for various reasons: firstly, as temperature was increased, the viscosity of the $\mathrm{Zn}$ electrolyte decreases, allowing an increase in the rate of mass transport toward the electrodes. Secondly, the Zn electrolyte contains a high concertation of $\mathrm{Cl}^{-}$anions ( $c a .5 \mathrm{M}$ ) which, through adsorption into the electrode surface, can impede the approach of $\left[\mathrm{ZnCl}_{4}\right]^{2-}$ towards the electrode surface. As the temperature of the electrolyte is increased, the number of adsorbed $\mathrm{Cl}^{-}$anions on the electrode surface tends to decrease, facilitating the approach of $\left[\mathrm{ZnCl}_{4}\right]^{2-}$ to the electrode surface and its subsequent reduction. ${ }^{30}$ From the cyclic voltammetry of $\mathrm{ZnCl}_{2}$ (Fig. 1) it can be seen that the rate electrodeposition of $\mathrm{Zn}$ from Ethaline at elevated temperature is considerably improved over that at room temperature.

\section{Effect of additives on the voltammetric behaviour of $\mathrm{Zn}$ (II)}

As can be concluded from Fig. 1, the electrodeposition of $\mathrm{Zn}$ from Ethaline at $80{ }^{\circ} \mathrm{C}$ is considerably better than at room temperature due to the increased efficiency and rate of deposition of $\mathrm{Zn}$. Therefore, in the subsequent electrodeposition of $\mathrm{Zn}$ from Ethaline these conditions were selected. Fig. 2 shows the cyclic voltammetry of $0.4 \mathrm{M} \mathrm{ZnCl}_{2}$ in Ethaline at $80^{\circ} \mathrm{C}$ in the absence and presence of different concentrations of the following additives: (a) nicotinic acid (NA), (b) boric acid (BA), and (c) $p$-benzoquinone (BQ). 
The cyclic voltammograms were recorded at a scan rate of $30 \mathrm{mVs}^{-1}$ using a $1.0 \mathrm{~mm} \mathrm{Pt}$ disc electrode, a Pt flag counter-electrode and an $\mathrm{Ag} / \mathrm{AgCl}$ reference electrode. The concentrations used were influenced by the work by Juma which in turn were limited by solute solubility. ${ }^{31}$

In the absence of additive (Fig. 2), the onset of $\mathrm{Zn}^{2+}$ reduction (vs. $\mathrm{Ag} / \mathrm{AgCl}$ ) in Ethaline is at $\mathrm{E}=-1.18 \mathrm{~V}$ and the oxidation of $\mathrm{Zn}$ occurs via a two-stage process, with two oxidation peaks at $\mathrm{E}=-0.95 \mathrm{~V}$ and at $-0.85 \mathrm{~V}$. The two stripping peaks corresponded to the presence of two energetically distinct phases of $\mathrm{Zn}$. This was shown in previous studies using solution phase and ex-situ electrochemical atomic force microscopy. ${ }^{32,33}$ The deposition and stripping processes of $\mathrm{Zn}$ have been altered as a result of including NA, as shown in Fig. 2 (a). A clear decrease in the magnitude of the reduction peak currents can be seen with an increasing amount of NA in the electrolyte. In addition, a negative shift of around $30 \mathrm{mV}$ in the $\mathrm{Zn}^{2+}$ reduction potential occurred as NA was introduced to the $\mathrm{Zn}$ electrolyte. The negative shift in the overpotential for the reduction of $\mathrm{Zn}^{2+}$ can be attributed to the adsorption of NA on the electrode surface, ${ }^{28,34}$ thus requiring additional energy to discharge the $\mathrm{Zn}^{2+}$ ions.

The adsorption of NA on different substrates has been confirmed in other studies by Auger and SERS spectroscopy. ${ }^{28,35,36}$ NA can be adsorbed on the electrode surface through the lone pair of electrons on either its nitrogen or oxygen atom, or both. ${ }^{36,37} \mathrm{NA}$ molecules can be absorbed on the surface in different ways, namely perpendicular or parallel to the electrode surface, as shown in Fig. 3.

It can be seen from Fig. 2 (a) that the deposition and stripping peaks of $\mathrm{Zn}$ decreased when $0.03 \mathrm{M}$ NA was added to the Zn electrolyte. However, increasing the concentration of NA results in an optimum concentration of NA at close to $0.05 \mathrm{M}$, Fig 2 (a). Further increase in NA concentration results in a sustained decrease in current peak magnitude. This behaviour could be related to the adsorption position of NA on the electrode surface. The parallel adsorption position of NA on the electrode surface (as shown in Fig. 3) can block a large area of the surface, and this may be more prevalent when a low concentration of NA is present in the bath. Perpendicular NA adsorption could occur when one increases the concentration of NA, where this orientation only blocks a small area of the surface and thus allows for a relatively increased amount of $\mathrm{Zn}$ deposition. At higher NA concertation the peak attenuation could be exacerbated by multi-layer adsorption. 
In contrast, both BA and BQ show sustained attenuation of the voltammertic peaks with increase in concentration of additive, Fig. 2 (b) and (c). An obvious decrease in the deposition of $\mathrm{Zn}$ occurred with an increasing concentration of BA, and a negative shift in the $\mathrm{Zn}$ reduction potential was also produced as a result of adding of $\mathrm{BA}$ to the $\mathrm{Zn}$ electrolyte. In aqueous electrodeposition, boric acid is often used to prevent an increase in $\mathrm{pH}$ at the cathodic electrode. However, it has been reported in the literature that that BA can be adsorbed onto the electrode surface. ${ }^{38,39}$ The behaviour of BA in DES is currently undetermined. However, a bright and smooth $\mathrm{Zn}$ deposit was achieved when BA was added to Ethaline containing a $0.4 \mathrm{M} \mathrm{ZnCl}_{2}$ solution. Therefore, it is likely that the $\mathrm{BA}$ in the $\mathrm{Zn}$ bath could be absorbed onto the cathode surface and inhibit $\mathrm{Zn}$ deposition.

\section{Voltammetric behaviour of additives in Ethaline}

The electrochemical behaviour of NA, BA and BQ was examined by $\mathrm{CV}$ in neat electrolyte (i.e. in the absence of zinc salt), Ethaline at $80^{\circ} \mathrm{C}$. Fig. 4 shows the cyclic voltammetry of Ethaline in the absence and presence of NA, M BA and BQ at $80{ }^{\circ} \mathrm{C}$ on a Pt disk electrode (vs. an $\mathrm{Ag} / \mathrm{AgCl}$ reference). Fig. 4 (a) demonstrates the cyclic voltammetry of Ethaline in the absence and presence of different concentrations of NA at $80{ }^{\circ} \mathrm{C}$, where in the cyclic voltammetry of Ethaline a reduction peak was obtained at about $-1.0 \mathrm{~V}$. This peak corresponded to hydrogen evolution, but is shifted positively by $20 \mathrm{mV}$ at a concentration of $0.05 \mathrm{MNA}$ in the electrolyte. The shift and the increase in the reduction peak corresponded to an increase in hydrogen evolution. In Fig. 4 (a), a small reduction peak can be seen at about $-0.5 \mathrm{~V}$, which is associated with the reduction of NA. From Fig. 2 (a) and Fig. 4 (a), the onset potential of 0.4 M Zn without NA is more negative in comparison to the onset potential of NA in Ethaline by $-0.5 \mathrm{~V}$. This suggests that NA has been reduced and blocks the active points of the surface before $\mathrm{Zn}$ deposition. As a consequence of these differences in the potential, the cathodic reaction is more likely to be inhibited. It has been reported that voltammograms of NA dissolved in a pH 5.0 phosphate buffer saline on a polycrystalline gold electrode appear at a more positive potential. ${ }^{40}$ However, the cathodic peak is twice as high as the anodic peak current. 
As we have been using BA as a brightener in the electrodeposition of $\mathrm{Zn}$ from Ethaline, shows the cyclic voltammograms of different concentrations of BA in Ethaline at $80^{\circ} \mathrm{C}$. There is a clear new cathodic peak that has started to appear at about $-0.5 \mathrm{~V}$ as BA was introduced into the electrolyte, whose intensity increases with an increasing concentration of BA. Boric acid could be dissociated in Ethaline to form the $\left[\mathrm{H}_{2} \mathrm{BO}_{3}\right]^{-}$anion and $\mathrm{H}^{+}$. Therefore, the peak that started to appear at $-0.5 \mathrm{~V}$ could specifically correspond to the adsorption of BA on the Pt electrode surface that then reduces with the consequent evolution of hydrogen, or this peak could otherwise be attributed to the adsorption of dihydrogen borate on the electrode surface via a one-electron transfer reaction. EI-Shafei and Aramata reported that BA can be adsorbed on a Pt (111) surface in acidic aqueous solutions. ${ }^{41,42}$ They found that the specific adsorption of BA takes place at more positive potentials. This is could be due to the effect of the natural electrolyte and electrode substrate. Thus, from the voltammetry of BA in Ethaline, as shown in Fig. 4 (b), it can be suggested that BA is adsorbed on the electrode surface and inhibits $\mathrm{Zn}$ deposition.

Fig. 4 (c) shows the cyclic voltammograms recorded for different concentrations of BQ in Ethaline at $80^{\circ} \mathrm{C}$. Significant changes have occurred in the cyclic voltammograms of Ethaline through the use of BQ. The onset of cathodic reduction for Ethaline was at -0.9 V. However, using BQ, the onset of cathodic reduction was shown to occur at about -0.1 $\mathrm{V}$ where this corresponds to the reduction of BQ. As has been shown previously, Zn can be deposited in Ethaline at -1.18 V. Thus, it can be said that BQ adsorbs on the electrode surface and blocks the active sides before deposition of $\mathrm{Zn}$.

\section{Chronocoulometry}

Chronocoulometry (CC) data in the form of integrated Cottrell plots provide information regarding the reaction process and can be used to determine if a reaction is under masstransport or kinetic control. ${ }^{43}$ For example we have recently examined the chronocoulometry of $0.01 \mathrm{M} \mathrm{CuCl}_{2} .2 \mathrm{H}_{2} \mathrm{O}$ in Ethaline using a Pt disc electrode, and found that metal growth was diffusion controlled. ${ }^{17}$

In the current study, $\mathrm{Zn}$ chronocoulometry experiments were performed on a $\mathrm{Pt}$ disc electrode from Ethaline containing $0.4 \mathrm{M} \mathrm{ZnCl}_{2}$ at $80^{\circ} \mathrm{C}$ in the absence and presence of $0.05 \mathrm{M}$ nicotinic acid, $0.15 \mathrm{M}$ boric acid and $0.03 \mathrm{M}$ p-benzoquinone, as shown in Fig. 
5, where all experiments were performed for potential steps from $0.0 \mathrm{~V}$ (held for $10 \mathrm{~s}$ ) to $-1.3 \mathrm{~V}$ for $30 \mathrm{~min}$. Fig. 5 shows the plots of charge vs. $t^{1 / 2}$ are not linear suggesting that the processes are not controlled by diffusion. It is clear from Fig. 5 that the charge $(Q)$ for $\mathrm{Zn}$ deposition in the presence of additives decreased. This indicates that electrodeposition of $\mathrm{Zn}$ from an additive-free system is faster than in a system containing additives; the same conclusion was drawn from the results of our cyclic voltammetry. According to Faraday's Law $(Q=n F N)$, the charge measured is directly proportional to the number of species deposited in moles $(N)$. This means that current efficiency of $\mathrm{Zn}$ deposition from Ethaline in the presence of additives will be less than the efficiency of $\mathrm{Zn}$ deposition from an additive-free electrolyte. The current efficiencies of $\mathrm{Zn}$ electrodeposition from Ethaline in the absence and presence of these additives were investigated using a quartz crystal microbalance (QCM), which will be discussed later.

\section{Nucleation mechanisms}

In order to further probe the possible change in the mechanism of $\mathrm{Zn}$ reduction, the nucleation mechanism needs to be investigated. Therefore, the chronoamperometry method was used to study the nucleation mechanism of $\mathrm{Zn}$ deposition. The chronoamperometric study was performed using a potential between $-0.50 \mathrm{~V}$ to $-1.25 \mathrm{~V}$ with a polished Pt disk vs. $\mathrm{Ag} / \mathrm{AgCl}$.

To identify trends in nucleation mechanisms of metal electrodeposition, a number of methods have been devised, the most widely used being the model developed by Scharifker and Hills, ${ }^{44}$ which allows chronoamperometric data to be assigned to one of two limiting nucleation mechanisms, instantaneous or progressive. In an instantaneous nucleation process, the model assumes the rate of nucleation is high and that coverage of all active sites by nuclei is essentially instantaneous. This process is described by Equ. 1:

$$
\left(\frac{i}{i_{m}}\right)^{2}=\frac{1.9542}{\frac{t}{t_{m}}}\left\{1-\exp \left[-1.2654\left(\frac{t}{t_{m}}\right)\right]\right\}^{2}
$$

Equation 1.

In the progressive nucleation mechanism, the rapid growth of a large number of active sites is achieved throughout the reduction, a process which is described by Equ. 2: 


$$
\left(\frac{i}{i_{m}}\right)^{2}=\frac{1.2254}{\frac{t}{t_{m}}}\left\{1-\exp \left[-2.3367\left(\frac{t}{t_{m}}\right)\right]^{2}\right\}^{2}
$$

\section{Equation 2}

In both processes, $i_{m}$ is the maximum current density and $t_{m}$ is the time taken to achieve $i_{m}$. Fig. 6 shows the normalised $i$ - $t$ curves associated with the theoretical models for threedimensional instantaneous and progressive nucleation as well as the experimental data for $\mathrm{Zn}$ deposited from Ethaline at $80^{\circ} \mathrm{C}$ in the absence and the presence of additives: (a) without additives, (b) $0.05 \mathrm{M} \mathrm{NA}$, (c) $0.15 \mathrm{M} \mathrm{BA}$ and (d) $0.03 \mathrm{M} \mathrm{BQ}$. When the overpotential is applied, the current initially rises quite sharply due to double layer charging, followed by a relaxation in current. A subsequent rise to the current maximum, indicative of a nucleation process, is then observed. This current increase is proposed by Scharifker and Hills to be caused by the formation and growth of nuclei. As the individual nuclei growth zones begin to overlap, the current falls to a level indicative of a diffusion-limited process.

The nucleation mechanism for $\mathrm{Zn}$ deposition on a Pt electrode from Ethaline without additives using the Scharifker-Hills model is shown in Fig. 6 (a), where the nucleation mechanism fits quite well to that of a progressive growth process. However, at times beyond the current maximum, $\left(\mathrm{i} / \mathrm{i}_{\mathrm{m}}\right)$, the experimental data do not fit well to either model 2. The nucleation mechanism of $\mathrm{Zn}$ in the presence of NA and BA in Ethaline is shown in Fig. 6 (b) and (c), respectively, where the mechanism fits well with one describing progressive growth. The nucleation mechanism of $\mathrm{Zn}$ deposition in the presence of BQ also suggested a progressive growth mechanism in the early phases but fits better to an instantaneous growth model after a long period of time, as is clear in Fig. 6 (d). This suggests that with increasing induction time, the electrode surface is subject to a considerable blocking effect by additives. A transition between the two nucleation mechanisms has been reported for nucleation and growth processes controlled by mass transfer. $19,45,46,47$

\section{Gravimetric analysis}

In addition to the cyclic voltammetry, chronocoulometry and chronoamperometry, the Electrochemical Quartz Crystal Microbalance (EQCM) technique has been used to study 
the effect of NA, BA and BQ on current efficiency of $\mathrm{Zn}$ deposition from Ethaline. The QCM technique uses a resonant quartz crystal, where this crystal is used as a mass probe for the electrolytic deposition of the metal. The consequent change in resonant frequency of the quartz crystal corresponds to the mass of metal deposited. In this case the frequency data were derived from acoustic impedance spectra acquired during deposition. This methodology was adopted in order to rule out viscoelastic effects during deposition. Subsequently frequency data were converted into mass changes using the Sauerbrey equation. ${ }^{48}$ The data regarding the effect of the addition of $0.05 \mathrm{M} \mathrm{NA}, 0.15 \mathrm{M} \mathrm{BA}$ and $0.03 \mathrm{M} B \mathrm{~B}$ on the growth of $\mathrm{Zn}$ from Ethaline at $80^{\circ} \mathrm{C}$ are shown in Fig. 7.

The mass- charge data shown in Fig 7 are quite noisy and this is because of the low resonant amplitude of the quartz crystal in the DES media caused by the relatively high viscosity ( $c a 40 \mathrm{cP}$ at room temp.) Despite this, there are clear differences in the data for $\mathrm{Zn}$ deposition with and without the additives. In all the data sets (Fig. 7) there is a period at the beginning of the experiment where charge is passed but very little measured mass results. This is indicative of an induction period and can often be attributed to a substrate effect. Once the substrate is covered with depositing metal (here $\mathrm{Zn}$ ) then subsequent deposition is more effective. The current efficiencies are calculated from the slope of the mass-charge plots using Faraday's law and these data are presented in Table 1.

Fig. 7 shows the mass/charge traces for electrodeposition of $\mathrm{Zn}$ from Ethaline in the presence and absence of additives. From Fig. 7, the current efficiencies of $\mathrm{Zn}$ depositions from Ethaline in the presence and absence of $0.05 \mathrm{M} \mathrm{NA}, 0.15 \mathrm{M}$ BA and $0.03 \mathrm{M}$ BQ at $80^{\circ} \mathrm{C}$ were measured. Metallic $\mathrm{Zn}$ was deposited on a Pt-coated resonant quartz crystal under a constant potential of $-1.3 \mathrm{~V}$ from Ethaline-based liquids containing $0.4 \mathrm{M} \mathrm{ZnCl}_{2}$ at $80^{\circ} \mathrm{C}$ in the absence of additives.

The current efficiency for $\mathrm{Zn}$ deposition in the absence of additive is close to unity at $91 \%$. Addition of BA significantly reduces the current efficiency to $71 \%$ and this is accentuated with addition of NA which gives the lowest current efficacy at $52 \%$. The effect of reducing current efficiency for these additives is almost certainly due to proton reduction. Given that the NA concentration is significantly lower than the BA concentration in these experiments, these data tend to indicate that NA is a stronger acid in this DES medium. Addition of BQ does not have this effect because there are no labile, reducible protons available. The current efficiency observed for $\mathrm{Zn}$ deposition in the presence of BQ is $95 \%$ and very similar to $\mathrm{Zn}$ without additives. Given the noise levels 
present in the data (Fig. 7) the difference between these two numbers lies within the resolution of the measurement.

\section{Zinc deposit morphology}

Photographs, morphologies and cross-sections of $\mathrm{Zn}$ deposits that have been obtained from Ethaline with a concentration of $0.4 \mathrm{M} \mathrm{ZnCl}_{2}$ in the presence and absence of NA, BA and BQ are shown in Fig. 8. All Zn electrodepositions were achieved on $\mathrm{Cu}$ substrates at $80^{\circ} \mathrm{C}$ for $2 \mathrm{~h}$ at a current density of $3.3 \mathrm{~mA} \mathrm{~cm}$. Fig. 8 (a) shows the morphology of the $\mathrm{Zn}$ deposit that was obtained from an additive-free electrolyte, where it can be seen that different-sized $\mathrm{Zn}$ particles were obtained with a rough, polycrystalline morphology. Clear changes in the morphologies of the $\mathrm{Zn}$ deposit occurred when NA Fig. 8 (b), BA Fig. 8 (c) and BQ Fig. 8 (d), were added individually to the Zn electrolyte. In previous work, the effects of nicotinic acid on the electrodeposition of $\mathrm{Ni}$ (II) from DES were investigated. It was found that nicotinic acid inhibited Ni deposition; at the same time, it acted as a brightener, and produced highly uniform and smooth Ni deposits. 16 In this study, when NA was used in the Zn electrodeposition, a significant change was observed in the morphology of the $\mathrm{Zn}$ film. A bright $\mathrm{Zn}$ coating was deposited from Ethaline with a concentration of $0.4 \mathrm{M} \mathrm{ZnCl}_{2}$ and $0.05 \mathrm{M} \mathrm{NA}$. According to the voltammograms of NA in Ethaline, as shown in Fig. 4 (a), it can be suggested that NA adsorbs on the cathodic electrode and inhibits the deposition of $\mathrm{Zn}$. An improvement in the smoothness and refinement in the grain size of the $\mathrm{Zn}$ deposit, as can be seen in Fig. 8 (b), has been obtained as a result of using NA as an additive. Thus, NA can act as a very effective brightener in $\mathrm{Zn}$ deposition.

The cross-sectional morphology of the $\mathrm{Zn}$ coating deposited from the additive-free electrolyte is shown in Fig. 8 (a). It was found that the $\mathrm{Zn}$ coating exhibits good adhesion with the $\mathrm{Cu}$ substrate, and the thickness of the coating was uniform with an average value of $\sim 11.1 \mu \mathrm{m}$, as based on four thicknesses measured at random positions. A theoretical thickness for Zn film can be calculated based on Faraday's electrolysis law, and was found as $11.67 \mu \mathrm{m}$ for a deposition current density of $3.3 \mathrm{~mA} \mathrm{~cm}^{-2}$. Consequently, the current efficiency was about $\sim 95 \%$, which is close to the efficiency measured from QCM data, Table 1. The cross-sectional morphology of the $\mathrm{Zn}$ coating deposited from the electrolyte containing 0.05 M NA is shown in Fig. 8 (b), where small holes were observed 
in the cross-sectional morphology of the $\mathrm{Zn}$ film. The presence of these holes could correspond to hydrogen evolution occurring on the cathode surface during the electrodeposition process. The thickness of the $\mathrm{Zn}$ coating obtained from a system containing NA was increased compared to the above, being found as $15.4 \mu \mathrm{m}$, where the recorded increase in film thickness could be attributed to the presence of the small holes in the $\mathrm{Zn}$ film.

Fig. 8 (c) shows photographs, morphologies and cross sections of the $\mathrm{Zn}$ deposits obtained from a system containing boric acid. Boric acid is one of the most common compounds to be added to Ni electroplating baths. Researchers have suggested that when boric acid is added to the electroplating bath it acts as a buffering agent to stop or reduce the alkalisation process at the cathodic electrode, which normally occurs due to hydrogen evolution. ${ }^{42,49,50}$ However, several reports in the literature have confirmed that BA acts as a surfactant, ${ }^{50}$ and also that BA interferes with the metal nucleation processes. ${ }^{50,51,52}$ Supicová et al. ${ }^{50}$ found that the presence of high concentrations of boric acid in aqueous baths inhibited nickel deposition itself but improved the morphology, brightness, and adhesion of the deposited $\mathrm{Ni}$.

In this project, BA was used as a brightener during the electrodeposition of $\mathrm{Zn}$ from Ethaline. A significant change in the $\mathrm{Zn}$ film morphology, where a clear refinement in the grain size of the $\mathrm{Zn}$ was obtained, along with a bright $\mathrm{Zn}$ film resulting from the use of boric acid, is shown in Fig. 8 (c). Here, BA most likely adsorbs on the electrode surface as a neutral molecule and strongly inhibits the deposition of $\mathrm{Zn}$. The thickness of the $\mathrm{Zn}$ deposit was $6.9 \mu \mathrm{m}$ when the deposition was performed using $0.15 \mathrm{M}$ BA, a significant decrease compared to the thickness of $\mathrm{Zn}$ film obtained from the additive-free system. The decrease in the thickness of $\mathrm{Zn}$ film in the presence of BA could be due to the adsorption of BA onto the electrode surface, inhibiting the growth of $\mathrm{Zn}$ nuclei and enhancing nucleation rate.

Fig. 8 (d) shows optical photographs, the morphology and cross sections of the Zn deposit obtained from a system containing 0.03 M BQ. A bright and smooth $\mathrm{Zn}$ film was obtained as a result of adding BQ to the $\mathrm{Zn}$ electrolyte, and clear refinement in the crystal size of the Zn deposit can be observed in Fig. 8 (d). However, a decrease in the thickness of the $\mathrm{Zn}$ film occurred when BQ was used. Here, BQ was thought to be adsorbed on the electrode surface thus inhibiting $\mathrm{Zn}$ deposition. 
Despite the fact that all the coatings were prepared for the same time at the same current density, the observed cross-section thicknesses do not follow the same thickness trend as might be expected based on the current efficiencies, Table 1. This may be because the time over which the QCM mass-charge data were measured over was 8.3 minutes, whereas the bulk deposition was carried out for $2 \mathrm{hrs}$. This indicates that the current efficiencies deviate at longer time scales perhaps due to bulk, progressive changes in the composition of the electrolyte.

\section{X-ray diffraction}

Here, the XRD technique was used to study the crystal orientations of $\mathrm{Zn}$ film produced from Ethaline in the presence and absence of additives. Fig. 9 shows XRD patterns for the $\mathrm{Zn}$ film obtained from Ethaline at a concentration of $0.4 \mathrm{M} \mathrm{ZnCl}_{2}$ in the absence and presence of $0.05 \mathrm{M}$ nicotinic acid, $0.15 \mathrm{M}$ boric acid and $0.03 \mathrm{M}$-benzoquinone, where all $\mathrm{Zn}$ film were achieved on $\mathrm{Cu}$ substrate at $80^{\circ} \mathrm{C}$, for $2 \mathrm{~h}$ at a current density of $3.3 \mathrm{~mA}$ $\mathrm{cm}^{-2}$. XRD patterns of the $\mathrm{Zn}$ film obtained from an additive-free system illustrate peaks at $2 \Theta=36.16^{\circ}, 38.9^{\circ}, 42.04^{\circ}, 54.32^{\circ}, 70.09^{\circ}, 82.16^{\circ}$ and $86.56^{\circ}$ which are related to the (002), (100), (101), (102), (103), (112) and (201) planes of hexagonal zinc, respectively. ${ }^{53}$ The diffraction peaks observed at $2 \Theta=43.2^{\circ}, 50.4^{\circ}$ and $74.14^{\circ}$ corresponded to the $\mathrm{Cu}$ substrate. It can be seen that the growth of $\mathrm{Zn}$ in the additive-free electrolyte preferentially takes place along the (002), (102) and (103) planes. ${ }^{53}$ However, Zn growth from an electrolyte containing nicotinic acid and boric acid is strongly directed along the (100), (110), (112) and (201) planes where as shown in Fig. 9 and Table. 2. No significant difference was noted in the crystal orientation of $\mathrm{Zn}$ film obtained from the system containing $p$-benzoquinone compared to that produced from the $\mathrm{Zn}$ electrolyte without any additive.

\section{Bright zinc deposits}

Brightness is related to the smoothness surface and its ability to reflect visible light without significant scattering, where roughness should be less than $400 \mathrm{~nm}$. Brightening can be defined as a deposit having crystals of a smaller size than the wavelength of visible light, which on average could be nominally taken to be smaller than $400 \mathrm{~nm}$. Small crystals are essential for brightness, but this in itself is not a satisfactory condition. A 
number of studies have found that brightness also depends on the orientation of crystallites that are deposited on the surface in the same plane. ${ }^{54} 47$

Bright $\mathrm{Zn}$ deposits have been obtained when the deposition has been achieved from Ethaline with $0.6 \mathrm{M} \mathrm{ZnCl}_{2}$ and $0.15 \mathrm{M} \mathrm{NA}$. Fig. 10 shows the morphology of a $\mathrm{Zn}$ film obtained from Ethaline with $0.6 \mathrm{M} \mathrm{ZnCl}_{2}$ in both the absence and presence of $0.15 \mathrm{M}$ $\mathrm{NA}$, where both experiments were performed at $80^{\circ} \mathrm{C}$ for $2 \mathrm{~h}$ at a current density of 6.15 $\mathrm{mA} \mathrm{cm}{ }^{-2}$. As mentioned earlier, NA can be adsorbed on the electrode surface and impede nucleation of large $\mathrm{Zn}$ crystals. It is clear from Fig. 10 that a $\mathrm{Zn}$ film obtained from a system without additives shows the unorganised deposition of $\mathrm{Zn}$ particles in random forms. However, a bright and highly smooth $\mathrm{Zn}$ film is produced when electroplating is achieved from Ethaline containing $0.6 \mathrm{M} \mathrm{ZnCl}_{2}$ and $0.15 \mathrm{M}$ of NA.

Earlier we have shown that, a $\mathrm{Zn}$ electrodeposit was produced from an electrolyte containing $0.4 \mathrm{M} \mathrm{ZnCl}_{2}$ with $0.05 \mathrm{M} \mathrm{NA}$ at a current density of $3.3 \mathrm{~mA} \mathrm{~cm}{ }^{-2}$ and that the addition of NA altered the morphology of the coating (Fig. 8). However, when the concentration of NA was increased ( $0.6 \mathrm{M} \mathrm{ZnCl}_{2}, 0.15 \mathrm{M} \mathrm{NA}$ and $\left.5 \mathrm{~mA} . \mathrm{cm}^{-2}\right)$, a bright, reflective $\mathrm{Zn}$ deposit was obtained after cleaning the $\mathrm{Zn}$ film surface, Fig. 10. As a consequence, the coating thickness was reduced from $16.17 \mu \mathrm{m}$ (in the absence of NA) to $11.8 \mu \mathrm{m}$ in the presence of $0.16 \mathrm{M} \mathrm{NA}$. This may due to a high concentration of NA, allowing its adsorption on the electrode surface and increasing the associated hydrogen evolution, which in turn could lead to a decrease in the thickness and current efficiency of $\mathrm{Zn}$ deposition.

The roughness and topography of the $\mathrm{Zn}$ films obtained from Ethaline in the absence and presence of NA were studied using AFM. Fig.10 illustrates the AFM image of a $\mathrm{Zn}$ deposit obtained from the electrodeposition of $0.6 \mathrm{M} \mathrm{ZnCl}_{2}$ in Ethaline in the absence and presence of $0.15 \mathrm{M}$ nicotinic acid at $80^{\circ} \mathrm{C}$. The roughness of the $\mathrm{Zn}$ film obtained from a solution containing NA was about $10 \mathrm{~nm}$; however, the roughness of the $\mathrm{Zn}$ film that was achieved from an additive-free solution was about $174 \mathrm{~nm}$.

Cyclic voltammograms of $0.6 \mathrm{M} \mathrm{ZnCl}_{2}$ in Ethaline in the absence and presence of 0.15 M NA are shown in Fig.11. The voltammetry was carried out in the potential range 0.0 $\mathrm{V}-1.5 \mathrm{~V}$ at a scan rate of $30 \mathrm{mVs}^{-1}$ using a Pt disc (1 mm diameter) electrode; a Pt flag was used as the counter-electrode, and $\mathrm{Ag} / \mathrm{AgCl}$ as the reference electrode. In the absence of NA, the onset of $\mathrm{Zn}$ reduction (vs. $\mathrm{Ag} / \mathrm{AgCl}$ ) in Ethaline was at $\mathrm{E}=-1.11 \mathrm{~V}$. However, 
this potential was shifted negatively by $15 \mathrm{mV}$ when $0.15 \mathrm{M}$ of NA was added to the $\mathrm{Zn}$ solution. Additionally, a significant decrease in the deposition/ dissolution of $\mathrm{Zn}$ occurred when NA was added to the Zn electrolyte. NA has been used in the electrodeposition of Ni from DES from which a bright and smooth Ni film was achieved, where it was suggested that NA adsorbed on electrode surface inhibited Ni deposition. ${ }^{28}$ Here, with Zn deposition, it can be similarly suggested that NA adsorbs on electrode surface and inhibits $\mathrm{Zn}$ deposition.

Cyclic voltammograms of NA in Ethaline were investigated, as shown previously in Fig.4 (a), and NA was deposited at a potential lower than that at of the $\mathrm{Zn}$ deposition potential. This means that NA adsorbs on the surface electrode and impedes $\mathrm{Zn}$ deposition. In Fig. 11, in the presence of NA, a small peak can be observed at $-0.47 \mathrm{~V}$ which corresponds to the hydrogen evolution that occurs as a result of its reduction. This confirms that NA adsorbs on the electrode surface and inhibits $\mathrm{Zn}$ deposition.

XRD patterns of $\mathrm{Zn}$ film obtained from $\mathrm{Zn}$ solutions in the absence and presence of nicotinic acid are shown in Fig. 12. In the case of the solution without NA, the $\mathrm{Zn}$ deposit shows the (002), (100), (101), (102), (103), (112) and (201) orientations and it has been shown that the growth of Zn preferentially takes place along the (002), (101), (102) and (103) planes; however, $\mathrm{Zn}$ growth from an electrolyte containing nicotinic acid preferentially take place along the (100) and (110) planes.

\section{Conclusions}

Organic additives are often added to aqueous electrodeposition baths as levellers and brighteners. However, few studies have considered the effects of additives on the electrodeposition of metals from deep eutectic solvents.

In this work, an investigation into the effects of additive addition to the $\mathrm{Zn}$ electrodeposition process from Ethaline has been presented. The additives studied, nicotinic acid, boric acid and $p$-benzoquinone, have been shown to have varying effects on the $\mathrm{Zn}$ deposition. Properties of the $\mathrm{Zn}$ electrodeposit have been improved compared to the corresponding system without additives, and for first time a mirror zinc coating has been achieved on a copper substrate when nicotinic acid was used as the additive. It was found that boric acid and $p$-benzoquinone work as brighteners for $\mathrm{Zn}$ deposition. 
Electrochemical experiments, including cyclic voltammetry, chronocoulometry and chronoamperometry, have established a clear difference in $\mathrm{Zn}$ electrodeposition processes when the additives were used and in the control experiments where no additive was used. Cyclic voltammetry has shown that these additives may be adsorbed on the electrode surface during the experiment and then inhibit $\mathrm{Zn}$ deposition. The morphologies of the $\mathrm{Zn}$ deposits using additives were improved compared to the corresponding systems without additives, showing considerable decreases in the roughness of the $\mathrm{Zn}$ films obtained when electrodeposition was achieved from a system containing an additive. Decreasing in the current efficiency of $\mathrm{Zn}$ deposition occurred when using these additives, especially with NA. In the XRD data shown, the (002), (101) and (102) planes were noted in the crystal orientation of the $\mathrm{Zn}$ film obtained from the system without additives. However, $\mathrm{Zn}$ growth from an electrolyte containing nicotinic acid and boric acid is strongly directed along the (100), (101) and (110) planes.

\section{Acknowledgements}

HFA wishes to acknowledge the financial support of Ministry of higher education and scientific research in Iraq, HCDP program is gratefully acknowledged for the studentship to Hasan Alesary. KSR wishes to thank Innovate UK for funding project CRUPPAIL (Cadmium Replacement Using Pulse Plating And Ionic Liquids), project no: 103530. 
Table.1: Current efficiencies of $\mathrm{Zn}$ deposition from Ethaline at a concentration of $0.4 \mathrm{M} \mathrm{ZnCl}_{2}$ in the absence and presence of $0.05 \mathrm{M} \mathrm{NA}, 0.15 \mathrm{BA}$ and $0.03 \mathrm{BQ}$. All experiments were performed on a Pt-coated EQCM crystal at $80^{\circ} \mathrm{C}$ and at an applied potential of $-1.3 \mathrm{~V}$.

\begin{tabular}{|c|c|}
\hline ChCl:EG:ZnCl 2 & $\begin{array}{c}\text { Cathode } \\
\text { Current efficiency \% }\end{array}$ \\
\hline 1:2: $0.4 \mathrm{M} \mathrm{Zn}$ & 91 \\
\hline 1:2: $0.4 \mathrm{M} \mathrm{Zn:} \mathrm{0.05} \mathrm{M} \mathrm{NA}$ & 52 \\
\hline 1:2: $0.4 \mathrm{M} \mathrm{Zn:} 0.15 \mathrm{M} \mathrm{BA}$ & 71 \\
\hline 1:2: $0.4 \mathrm{M} \mathrm{Zn:0.03} \mathrm{M} \mathrm{BQ}$ & 95 \\
\hline
\end{tabular}

Table. 2: Texture coefficients of the $\mathrm{Zn}$ deposits prepared from 1:2 ChCl:EG-based liquid containing $0.4 \mathrm{M} \mathrm{ZnCl}_{2}$ in the absence and presence of $0.05 \mathrm{M}$ nicotinic acid, $0.15 \mathrm{M}$ boric acid and $0.03 \mathrm{M}$ p-benzoquinone. All experiments were performed for $2 \mathrm{~h}$ at $80^{\circ} \mathrm{C}$ and at a current density of $3.3 \mathrm{~mA} \mathrm{~cm}^{-2}$.

\begin{tabular}{|c|c|c|c|c|c|c|}
\hline Component & $\begin{array}{c}\text { Relative } \\
\text { intensity } \\
{[\mathbf{0 0 2}]}\end{array}$ & $\begin{array}{c}\text { Relative } \\
\text { intensity } \\
{[\mathbf{1 0 0}]}\end{array}$ & $\begin{array}{c}\text { Relative } \\
\text { intensity } \\
{[\mathbf{1 0 2}]}\end{array}$ & $\begin{array}{c}\text { Relative } \\
\text { intensity } \\
{[\mathbf{1 0 3}]}\end{array}$ & $\begin{array}{c}\text { Relative } \\
\text { intensity } \\
{[112]}\end{array}$ & $\begin{array}{c}\text { Relative } \\
\text { intensity } \\
{[\mathbf{2 0 1}]}\end{array}$ \\
\hline Pure Zn & 0.402 & 0.118 & 0.154 & 0.162 & 0.098 & 0.064 \\
\hline $\mathrm{Zn}+\mathrm{NA}$ & 0.135 & 0.269 & 0.145 & 0.135 & 0.155 & 0.155 \\
\hline $\mathrm{Zn}+\mathrm{BA}$ & 0.152 & 0.250 & 0.148 & 0.147 & 0.148 & 0.153 \\
\hline $\mathrm{Zn}+\mathrm{BQ}$ & 0.324 & 0.150 & 0.168 & 0.165 & 0.101 & 0.090 \\
\hline
\end{tabular}




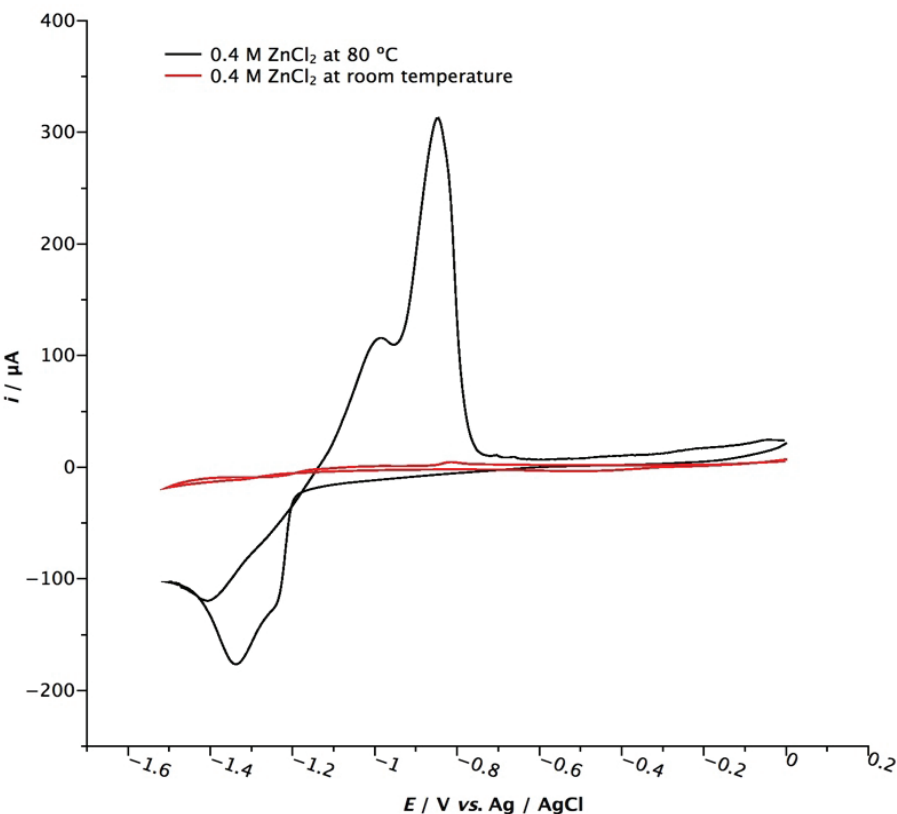

Figure 1: Cyclic voltammograms of $0.4 \mathrm{M} \mathrm{ZnCl}_{2}$ in Ethaline at $80^{\circ} \mathrm{C}$ (black line) and at room temperature (red line), recorded at a scan rate of $30 \mathrm{mV} \mathrm{s}^{-1}$, using a Pt disc (1 mm diameter) electrode, a Pt flag as the counter-electrode and $\mathrm{Ag} / \mathrm{AgCl}$ as the reference electrode. 


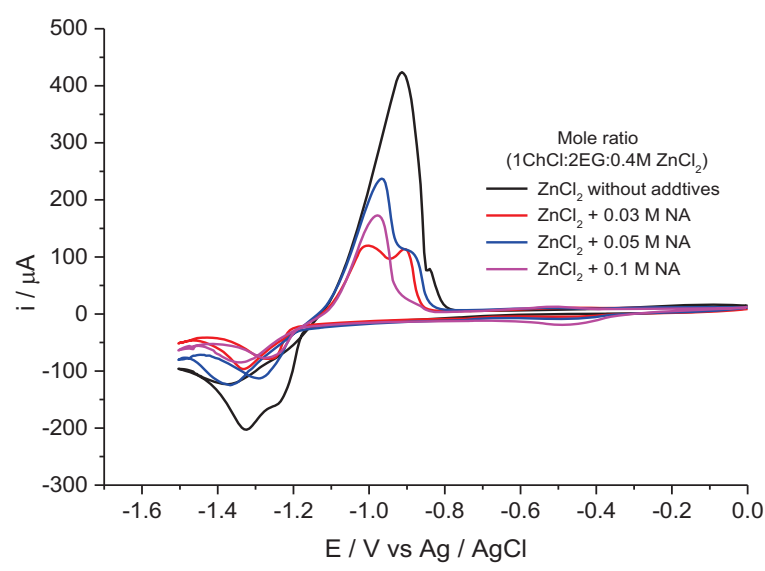

(a)

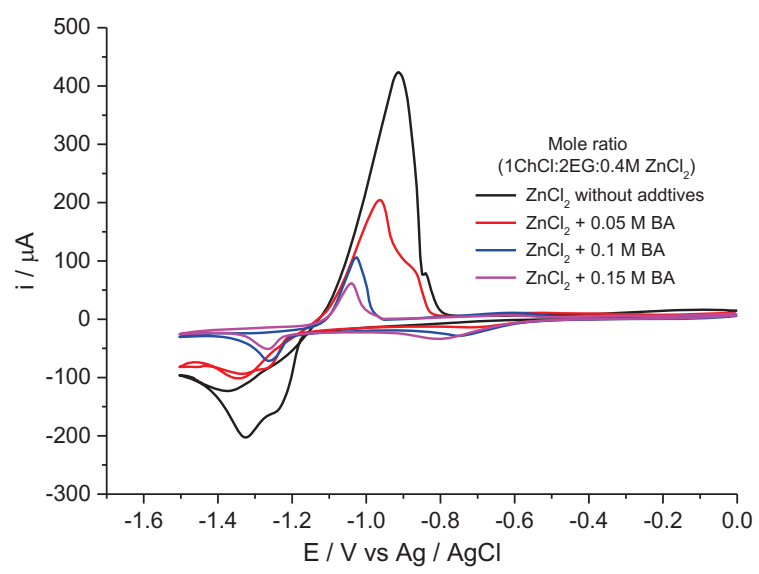

(b)

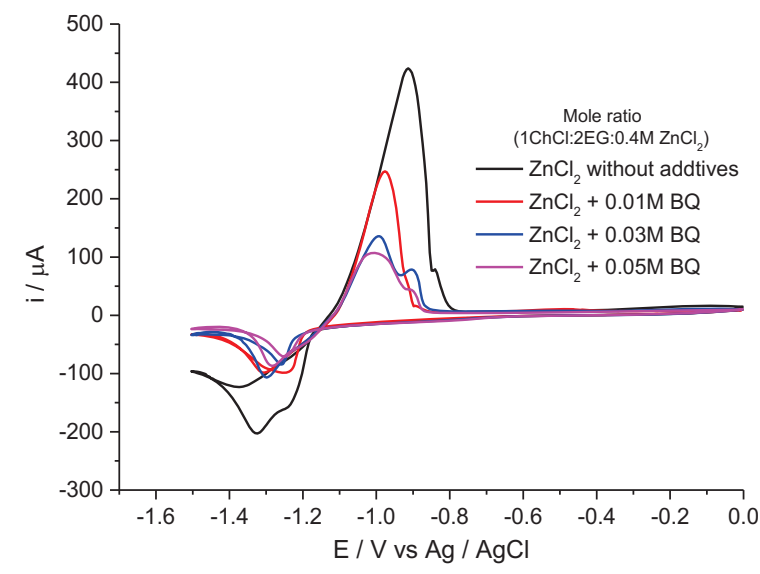

(c)

Figure 2: Cyclic voltammograms for $0.4 \mathrm{M} \mathrm{ZnCl}_{2}$ obtained from Ethaline, using a $\mathrm{Pt}$ disc electrode (1 mm diameter) at $80^{\circ} \mathrm{C}$ and at a scan rate of $30 \mathrm{mV} \mathrm{s}^{-1}$ with the following organic additives: (a) nicotinic acid, (b) boric acid, and (c) p-benzoquinone.<smiles>C[n+]1cccc(C(=O)O)c1</smiles>

2

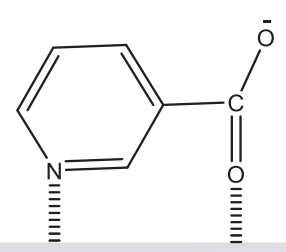

3

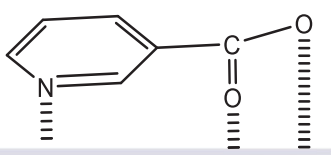<smiles>COC(=O)c1cccnc1</smiles>

Substrate

Figure 3: The orientation and probability of molecular adsorption of nicotinic acid. 


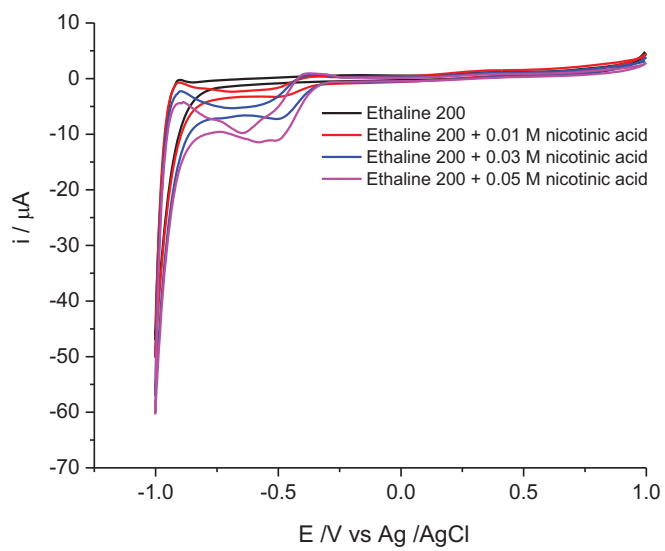

(a)

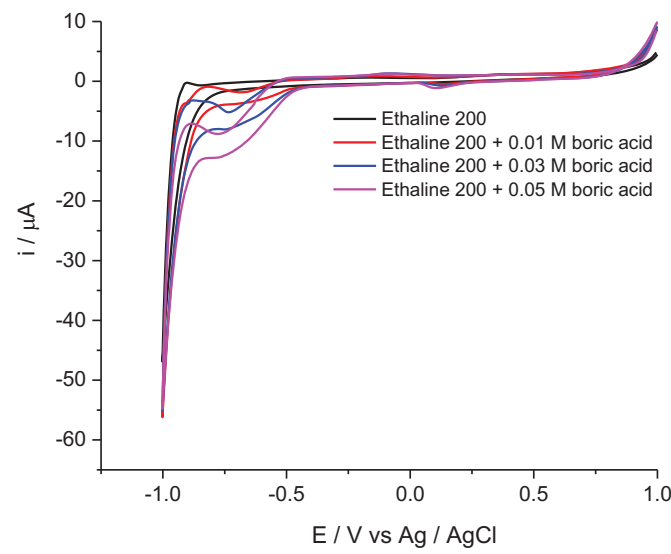

(b)

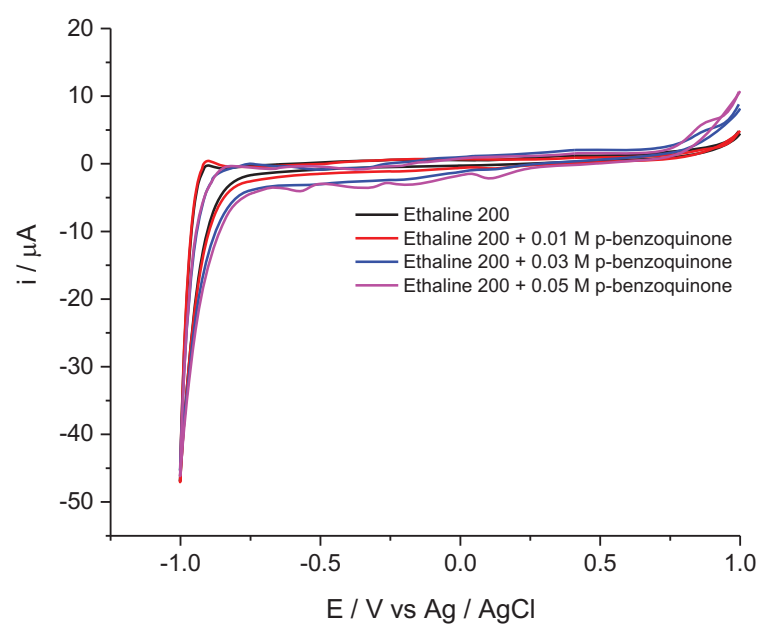

(c)

Figure 4: Cyclic voltammogram at $80{ }^{\circ} \mathrm{C}$ of Ethaline with varying amounts of (a) $\mathrm{NA}$, (b) BH and (c) BQ. Measured using a $1 \mathrm{~mm}$ Pt disc working electrode, Pt flag counter electrode and reference against $\mathrm{Ag} / \mathrm{AgCl}$ at $10 \mathrm{mV} \mathrm{s}^{-1}$. 


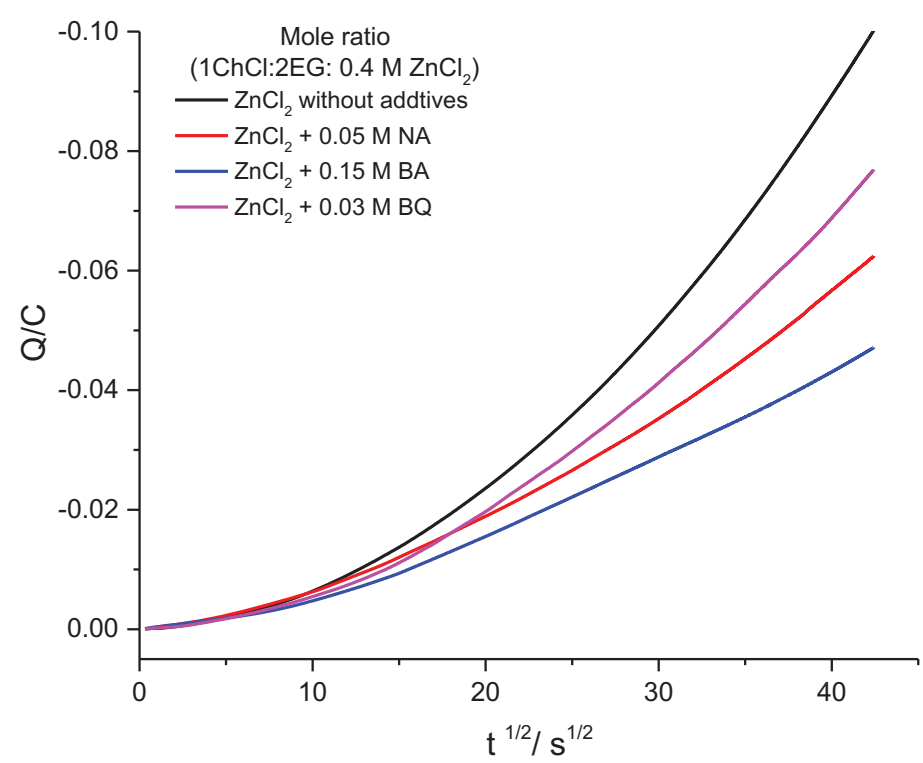

Figure 5: Chronocoulometry of $0.4 \mathrm{M}\left[\mathrm{ZnCl}_{2}\right]$ in Ethaline in the absence and presence of 0.05 $\mathrm{M} \mathrm{NA}, 0.2 \mathrm{M} \mathrm{BA}$ and $0.03 \mathrm{M} \mathrm{BQ}$. All experiments were achieved at a potential of $-1.3 \mathrm{~V}$ for $1800 \mathrm{~s}$ on $\mathrm{Pt}(1.0 \mathrm{~mm}$ diam $)$ and at $80^{\circ} \mathrm{C}$. 


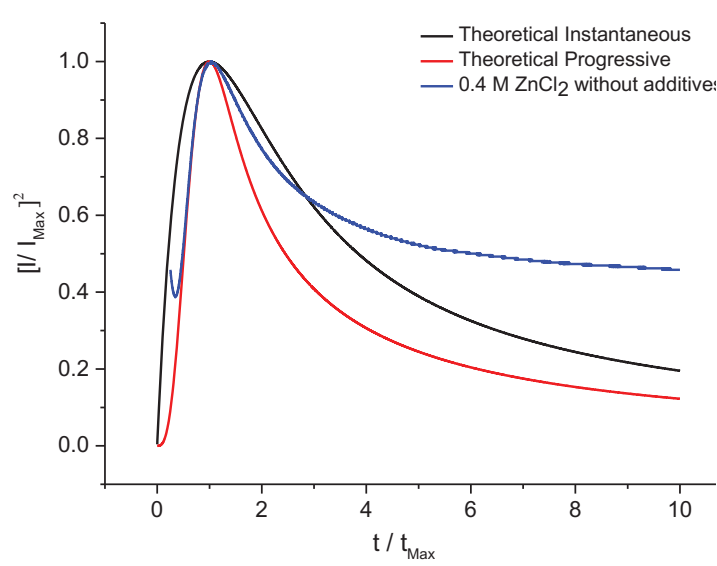

(a)

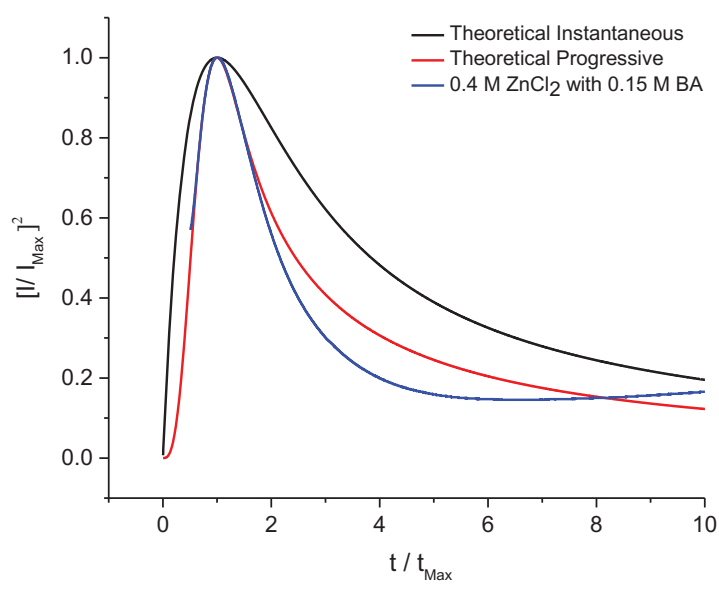

(c)

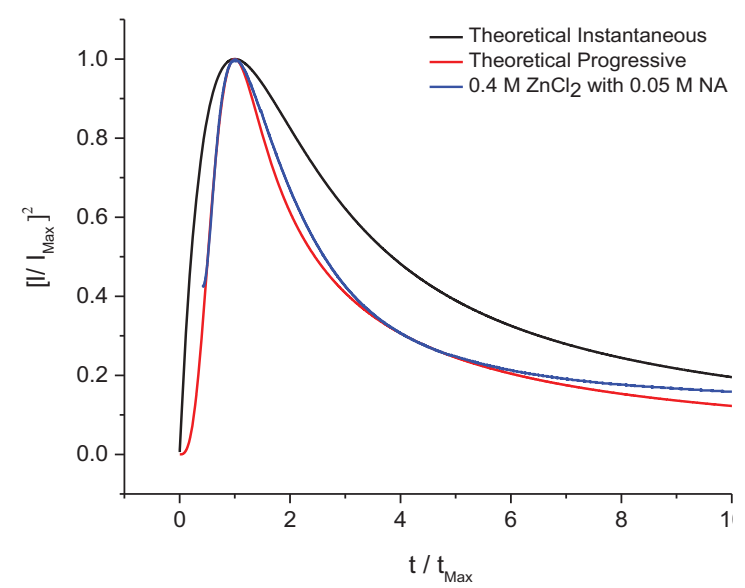

(b)

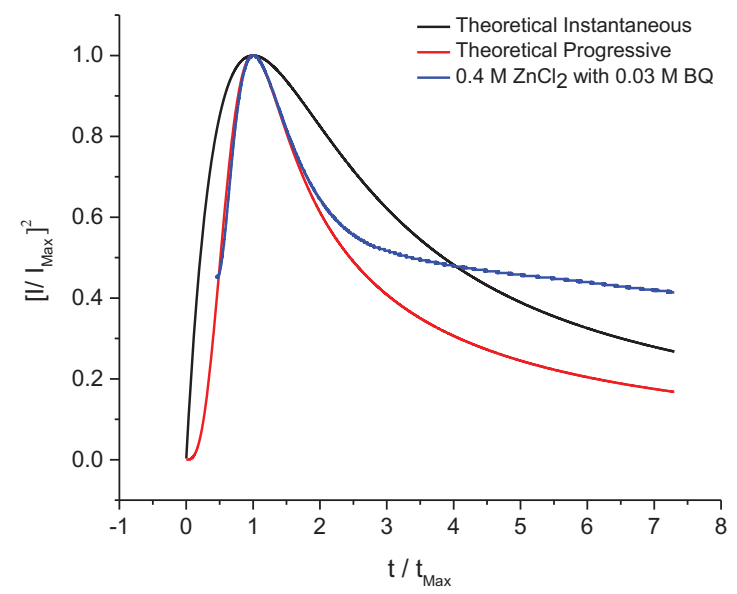

(b)

Figure 6: The experimental i-t data for electrodeposition of $0.4 \mathrm{M} \mathrm{ZnCl}_{2}$ from Ethaline on a $\mathrm{Pt}$ disc $\left(1 \mathrm{~mm}\right.$ diameter) at $80^{\circ} \mathrm{C}$ vs. an $\mathrm{Ag} / \mathrm{AgCl}$ reference electrode in the absence and presence of additives: (a) without additives; (b) $0.05 \mathrm{M} \mathrm{NA}$; (c) $0.15 \mathrm{M} \mathrm{BA}$; and (d) $0.03 \mathrm{M} \mathrm{BQ}$. The applied potential was $-1.25 \mathrm{~V}$ for all experiments. 


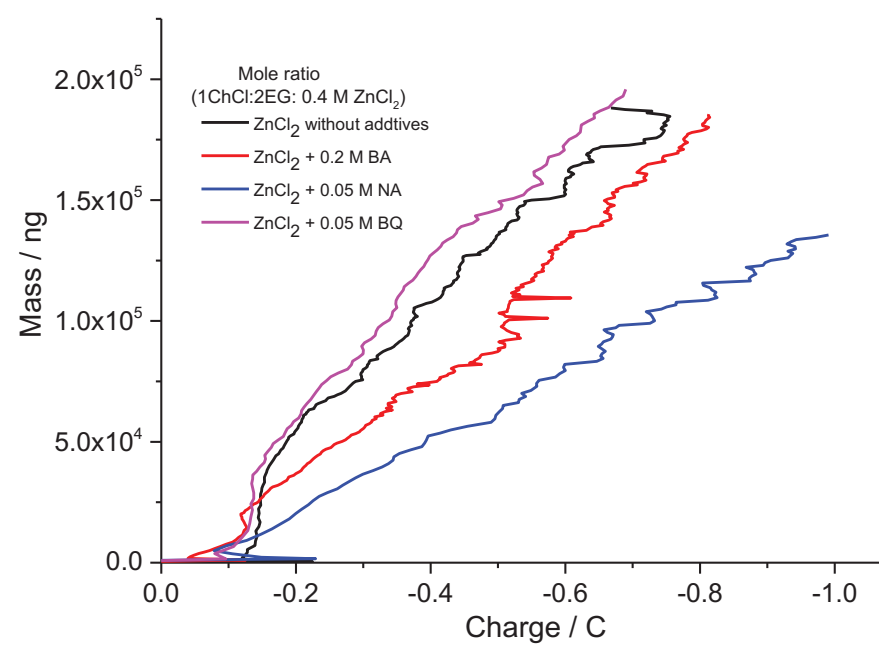

Figure 7: Gravimetric EQCM traces for Zn metal deposition on a Pt-coated quartz crystal (10 $\mathrm{MHz}$ ) surface in mass vs. charge. All experiments were performed in Ethaline at a concentration of $0.4 \mathrm{M} \mathrm{ZnCl}_{2}$ at $80^{\circ} \mathrm{C}$ in the presence and absence of additives. The applied potential was -1.3 V vs. $\mathrm{Ag} / \mathrm{AgCl}$ for $500 \mathrm{~s}$. 
Optical images

(a)

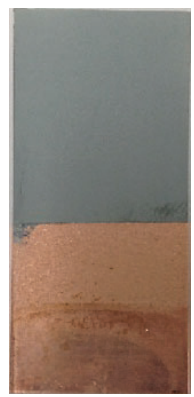

(b)

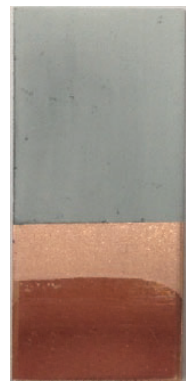

(c)

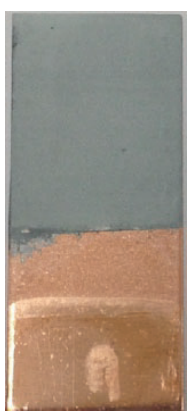

(d)

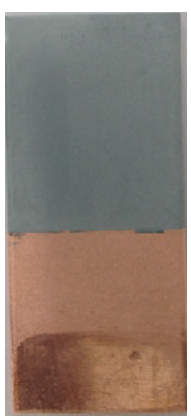

SEM
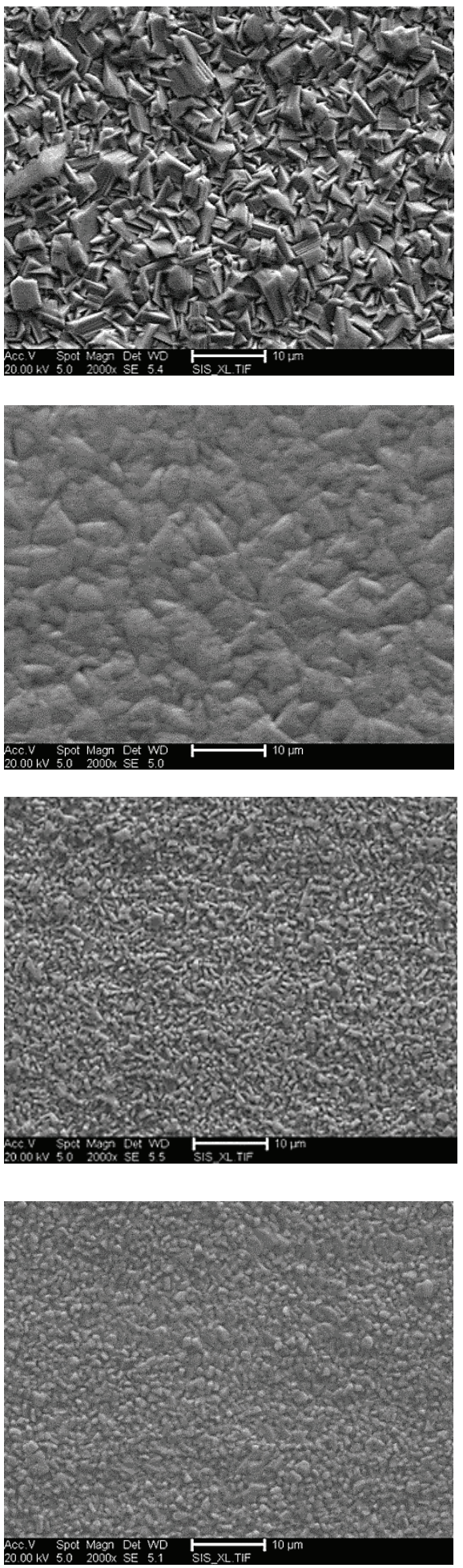

Cross section
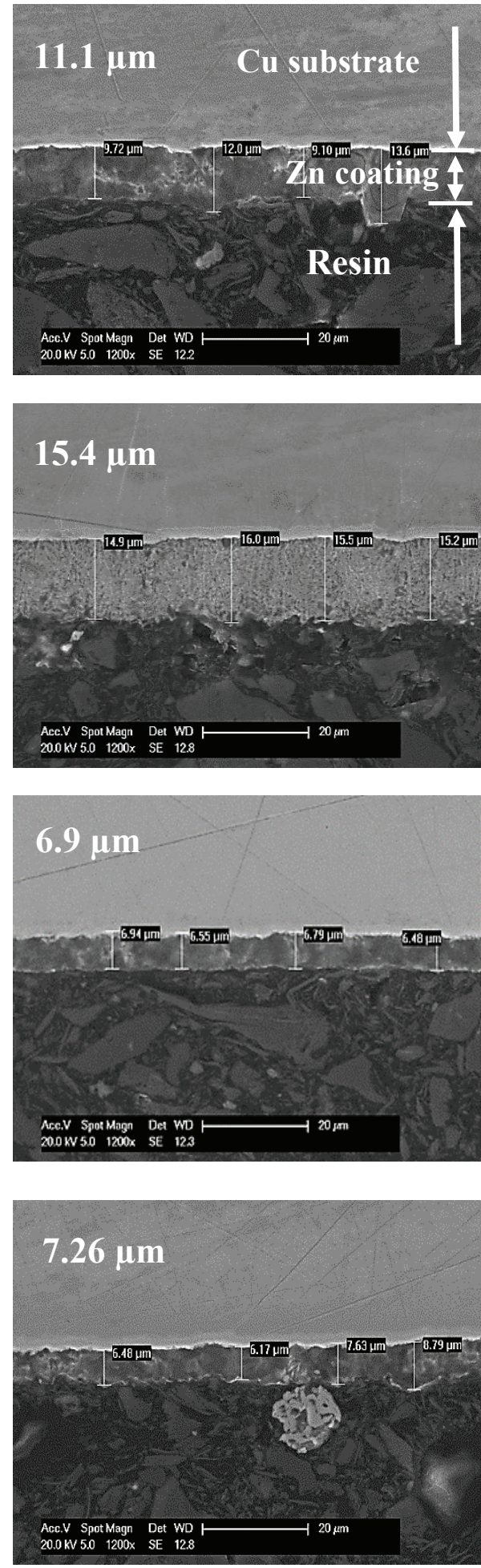

Figure 8: Optical photographs and SEM images with cross-sectional samples after bulk electrodeposition from Ethaline systems containing $0.4 \mathrm{M} \mathrm{ZnCl}_{2}$ using following additives: (a) without additives; (b) $0.05 \mathrm{M} \mathrm{NA}$; (c) $0.2 \mathrm{M} \mathrm{BA}$; and (d) $0.03 \mathrm{M} \mathrm{BQ}$. (All experiments were performed at $80^{\circ} \mathrm{C}$ for $2 \mathrm{~h}$ on a Cu electrode with an applied current density of $3.3 \mathrm{~mA} \mathrm{~cm}^{-2}$ ). 


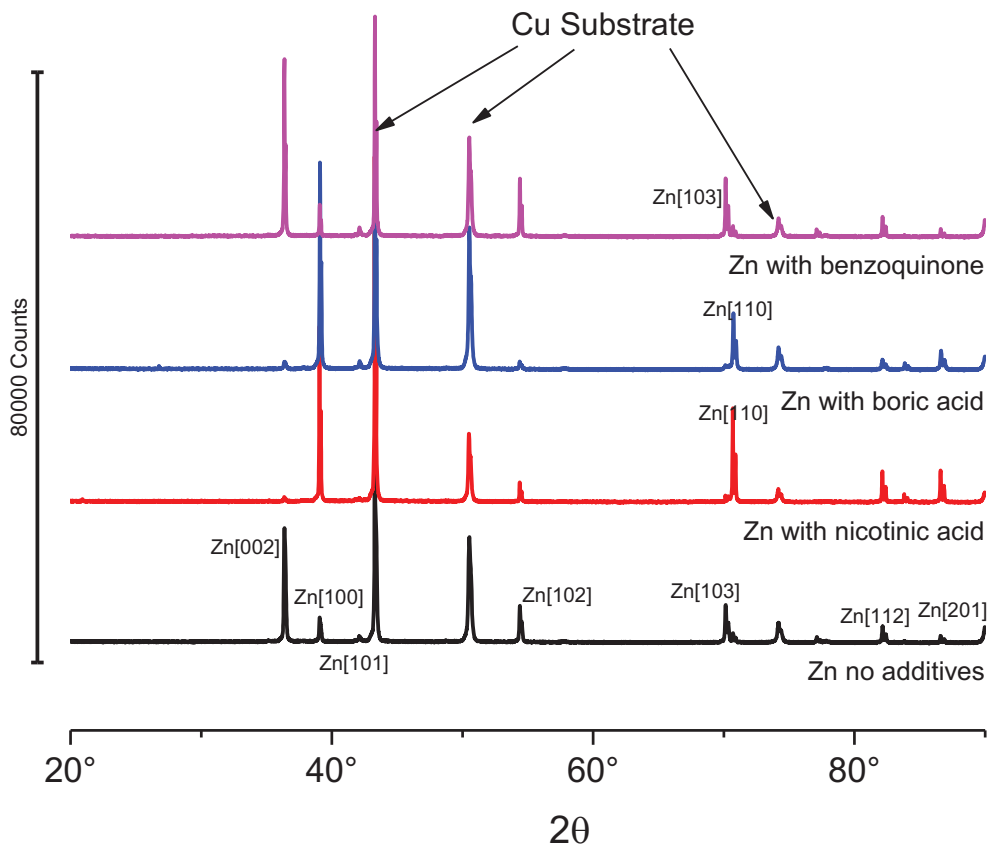

Figure 9: $\mathrm{XRD}$ patterns for $\mathrm{Zn}$ deposits from $0.4 \mathrm{M} \mathrm{ZnCl}_{2}$ in Ethaline with the following organic additives: $0.05 \mathrm{M}$ nicotinic acid, $0.15 \mathrm{M}$ boric acid and $0.03 \mathrm{M} \mathrm{p}$-benzoquinone. All experiments were performed for $2 \mathrm{~h}$ at $80^{\circ} \mathrm{C}$ and at a current density of $3.3 \mathrm{~mA} \mathrm{~cm}{ }^{-2}$. 

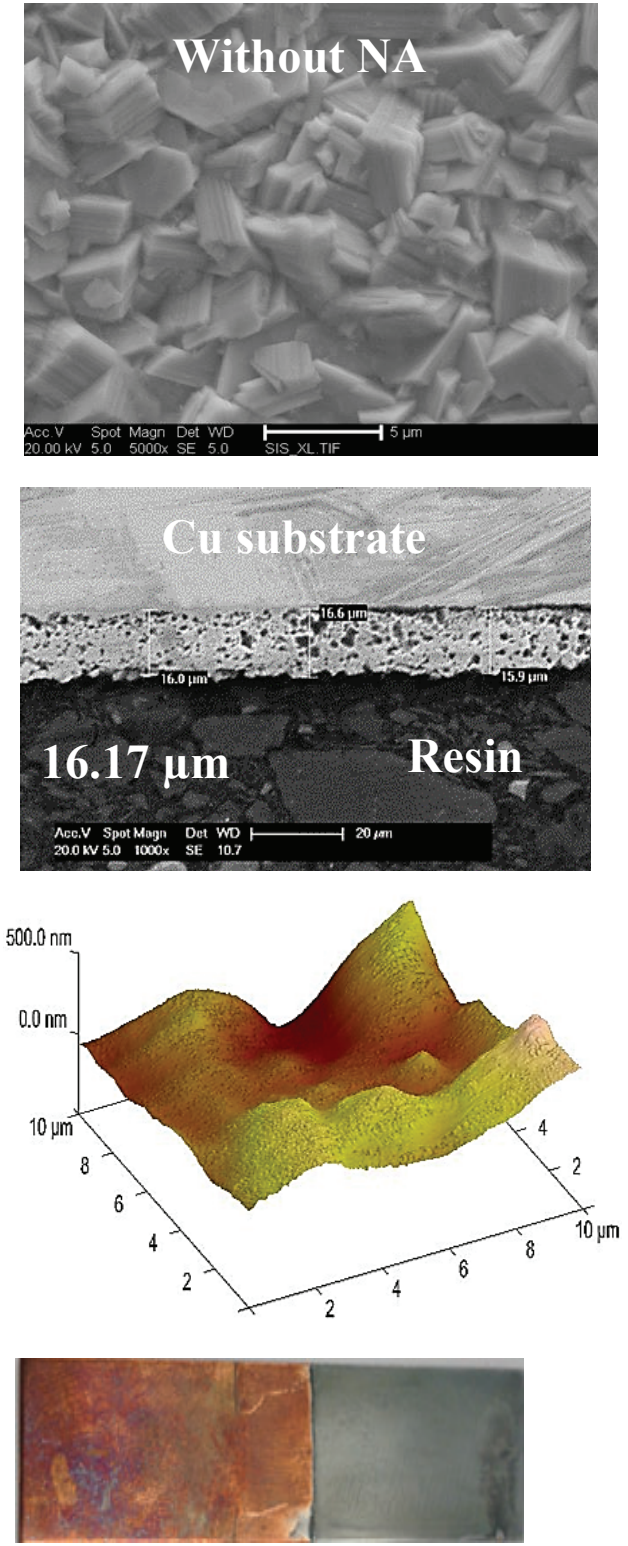

(a)
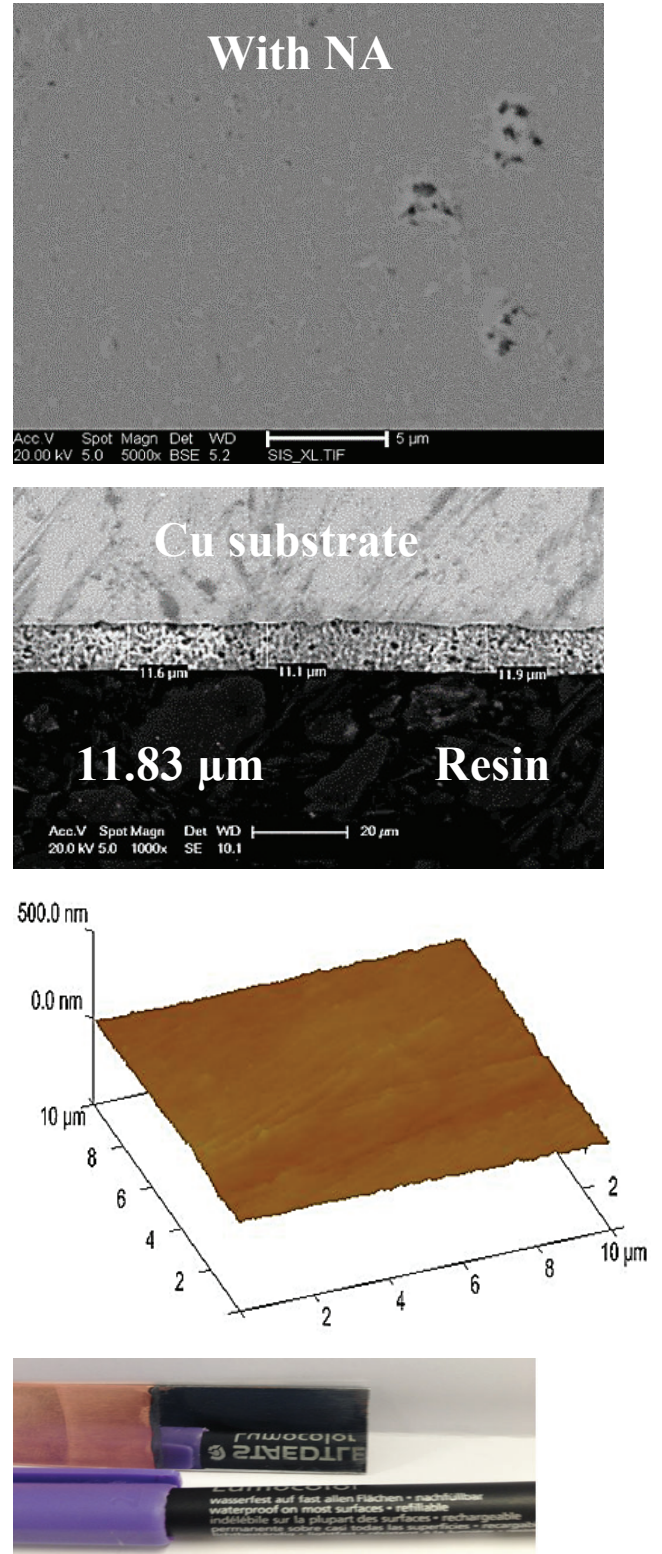

(b)

Figure10: Morphologies and AFM images of $\mathrm{Zn}$ films obtained from Ethaline in the absence and presence of NA, (a) without NA and (b) with NA. (the deposition was achieved from Ethaline with $0.6 \mathrm{M} \mathrm{ZnCl}_{2}$, with and without $0.15 \mathrm{M} \mathrm{NA}$, at a current density of $5 \mathrm{~mA} \mathrm{~cm}^{-2}$ for $2 \mathrm{~h}$ on a Cu substrate at $80^{\circ} \mathrm{C}$. 


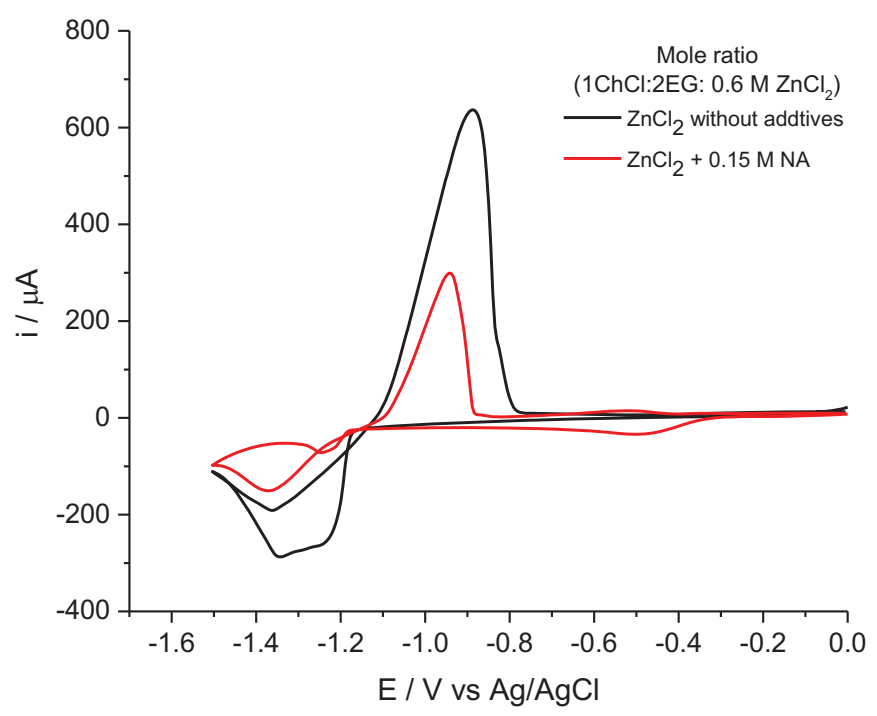

Figure 11: Cyclic voltammograms of $0.6 \mathrm{M} \mathrm{ZnCl}_{2}$ in Ethaline in the absence and presence of $0.15 \mathrm{M}$ nicotinic acid using a $\mathrm{Pt}$ disc (1 mm diameter) electrode, a Pt flag counter electrode and $\mathrm{Ag} / \mathrm{AgCl}$ as the reference electrode at $30 \mathrm{mVs}^{-1}$ and $80^{\circ} \mathrm{C}$.

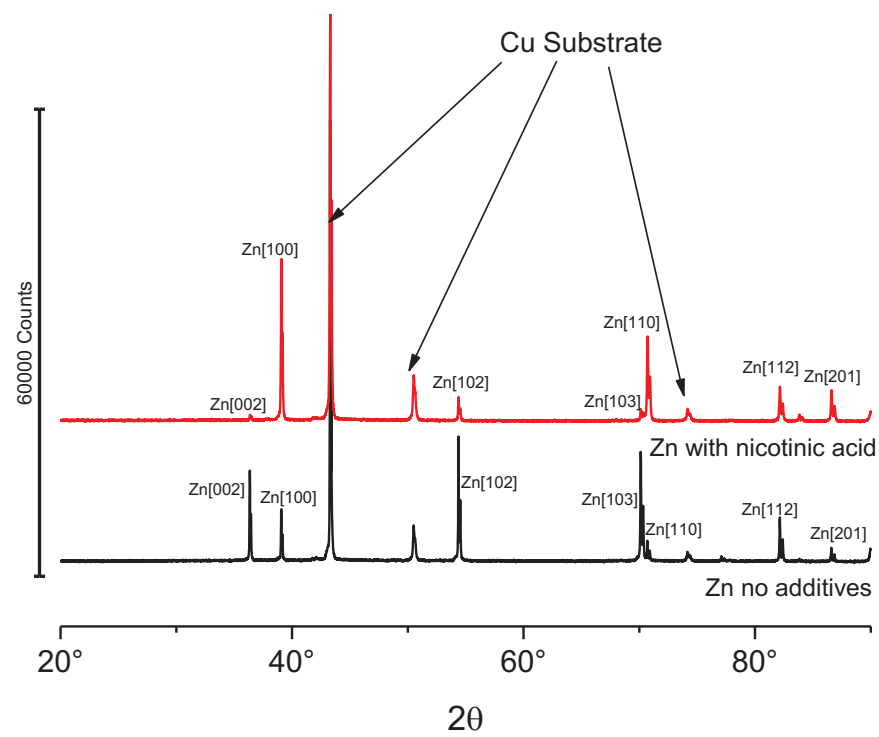

Figure 12: $\mathrm{XRD}$ patterns for $\mathrm{Zn}$ deposits from $0.6 \mathrm{M} \mathrm{ZnCl}_{2}$ in Ethaline in the absence and presence of $0.15 \mathrm{M}$ nicotinic acid, $0.15 \mathrm{M}$ boric acid and $0.03 \mathrm{M}$ p-benzoquinone. All experiments were performed for $2 \mathrm{~h}$ at $80^{\circ} \mathrm{C}$ and at a current density of $6.5 \mathrm{~mA} \mathrm{~cm}{ }^{-2}$. 


\section{References}

1 A. P. Abbott, J. C. Barron, G. Frisch, K. S. Ryder and A. F. Silva, Electrochimica Acta, 2011, 56, 5272-5279

2 F. Endres, D. MacFarlane and A. Abbott, Electrodeposition from ionic liquids, John Wiley \& Sons 2008

3 G. H. Lane, A. S. Best, D. R. MacFarlane, M. Forsyth and A. F. Hollenkamp, Electrochimica Acta, 2010, 55, 2210-2215.

4 S. Ibrahim, A. Bakkar, E. Ahmed and A. Selim, Electrochimica Acta, 2016, 191, $724-$ 732.

$5 \quad$ S. Müller, F. Holzer and O. Haas, Journal of Applied Electrochemistry, 1998, 28, 895898.

6 X. Zhai, C. Sun, K. Li, M. Agievich, J. Duan and B. Hou, Journal of Industrial and Engineering Chemistry, 2016, 36, 147-153.

7 R. Krishnan, S. Natarajan, V. Muralidharan and G. Singh, Plating and Surface Finishing, 1992, 79, 67-70.

8 M. Pushpavanam, Journal of Applied Electrochemistry, 2006, 36, 315-322.

9 Q. Zhang, K. D. O. Vigier, S. Royer and F. Jérôme, Chemical Society Reviews, 2012, 41, 7108-7146.

10 L. Vieira, R. Schennach and B. Gollas, Electrochimica Acta, 2016, 197, 344-352.

11 A. P. Abbott, D. Boothby, G. Capper, D. L. Davies and R. K. Rasheed, Journal of the American Chemical Society, 2004, 126, 9142-9147.

12 A. Paiva, R. Craveiro, I. Aroso, M. Martins, R. L. Reis and A. R. C. Duarte, ACS Sustainable Chemistry \& Engineering, 2014, 2, 1063-1071.

13 K. Haerens, E. Matthijs, A. Chmielarz and B. Van der Bruggen, Journal of Environmental Management, 2009, 90, 3245-3252.

14 N. M. Pereira, P. M. Fernandes, C. M. Pereira and A. F. Silva, Journal of The Electrochemical Society, 2012, 159, D501-D506.

15 M. Hayyan, M. A. Hashim, A. Hayyan, M. A. Al-Saadi, I. M. AlNashef, M. E. Mirghani and O. K. Saheed, Chemosphere, 2013, 90, 2193-2195.

16 E. L. Smith, A. P. Abbott and K. S. Ryder, Chemical Reviews, 2014, 114, 11060-11082.

17 A. P. Abbott, K. El Ttaib, G. Frisch, K. J. McKenzie and K. S. Ryder, Phys. Chem. Chem. Phy., 2009, 11, 4269-4277.

18 J. C. Barron, PhD thesis, University of Leicester, 2010.

19 G. Trejo, H. Ruiz, R. O. Borges and Y. Meas, Journal of Applied Electrochemistry, 2001, 31, 685-692.

20 J.-Y. Lee, J.-W. Kim, M.-K. Lee, H.-J. Shin, H.-T. Kim and S.-M. Park, Journal of the Electrochemical Society, 2004, 151, C25-C31.

21 J. J. Kelly, C. Tian and A. C. West, Journal of the Electrochemical Society, 1999, 146, 2540-2545.

22 T. Iwagishi, H. Yamamoto, K. Koyama, H. Shirai and H. Kobayashi, Electrochemistry, 2002, 70, 671-674.

23 K. Koyama, T. Iwagishi, H. Yamamoto, H. Shirai and H. Kobayashi, Electrochemistry (Japan), 2002, 70, 178-182.

24 A. P. Abbott and K. J. McKenzie, Physical Chem. Chem. Phys., 2006, 8, 4265-4279.

25 F. Endres, M. Bukowski, R. Hempelmann and H. Natter, Angewandte Chemie International Edition, 2003, 42, 3428-3430.

26 Z. Liu, S. Z. El Abedin and F. Endres, Electrochimica Acta, 2013, 89, 635-643. 
27 P.-Y. Chen and I.-W. Sun, Electrochimica Acta, 2001, 46, 1169-1177.

28 H. Yang, X. Guo, N. Birbilis, G. Wu and W. Ding, Applied Surface Science, 2011, 257, 9094-9102.

29 A. P. Abbott, A. Ballantyne, R. C. Harris, J. A. Juma and K. S. Ryder, Phys. Chem. Chem., Phys., 2017, 19. 3219.

30 A. P. Abbott, J. C. Barron, G. Frisch, S. Gurman, K. S. Ryder and A. F. Silva, Phys. Chem. Chem. Phys., 2011, 13, 10224-10231.

31 J. Juma, PhD thesis, University of Leicester, 2017.

32 Andrew P. Abbott, John C. Barron, Karl S. Ryder and Emma L. Smith, Anal. Chem., 2009, 81, 8466-8471.

33 Andrew P.Abbott, John C. Barron and Karl S. Ryder, Trans. IMF, 2009, 87, 201-207.

34 J. L. Ortiz-Aparicio, Y. Meas, G. Trejo, R. Ortega, T. W. Chapman and E. Chainet, Journal of Applied Electrochemistry, 2013, 43, 289-300.

35 J. Barthelmes, G. Pofahl and W. Plieth, J. Electroanal. Chem., 1993, 349, 223-231.

36 N. Batina, D. G. Frank, J. Y. Gui, B. E. Kahn, C.-H. Lin, F. Lu, J. W. McCargar, G. N. Salaita, D. A. Stern and D. C. Zapien, Electrochimica Acta, 1989, 34, 1031-1044.

37 J. Y. Gui, B. E. Kahn, L. Laguren-Davidson, C. H. Lin, F. Lu, G. N. Salaita, D. A. Stern and A. T. Hubbard, Langmuir, 1989, 5, 819-828.

38 N. Zech and D. Landolt, Electrochimica Acta, 2000, 45, 3461-3471.

39 J. Horkans, Journal of the Electrochemical Society, 1979, 126, 1861-1867.

40 X. Wang, N. Yang and Q. Wan, Electrochimica acta, 2006, 52, 361-368.

41 A. El-Shafei and A. Aramata, Journal of Solid State Electrochemistry, 2007, 11, 430-433.

42 C. Davalos, J. Lopez, H. Ruiz, A. Méndez, R. Antano-Lopez and G. Trejo, Int J Electrochem Sci, 2013, 8, 9785.

43 A. I. Alhaji, $\mathrm{PhD}$ thesis, University of Leicester, 2012.

44 B. Scharifker and G. Hills, Electrochimica Acta, 1983, 28, 879-889.

45 G. Gunawardena, G. Hills and I. Montenegro, Journal of Electroanalytical Chemistry and Interfacial Electrochemistry, 1985, 184, 371-389.

46 G. Gunawardena, G. Hills, I. Montenegro and B. Scharifker, Journal of Electroanalytical Chemistry and Interfacial Electrochemistry, 1982, 138, 225-239.

47 M. S. Cruz, F. Alonso and J. Palacios, Journal of Applied Electrochemistry, 1993, 23, 364-370.

48 G. Sauerbrey, Z. Phys., 1959, 155, 202.

49 J. Ji, W. Cooper, D. Dreisinger and E. Peters, Journal of Applied Electrochemistry, 1995, 25, 642-650.

50 M. Šupicová, R. Rozik, L. Trnková, R. Oriňáková and M. Gálová, Journal of Solid State Electrochemistry, 2006, 10, 61-68.

51 C. Karwas and T. Hepel, Journal of the Electrochemical Society, 1988, 135, 839-844.

52 C. Karwas and T. Hepel, Journal of the Electrochemical Society, 1989, 136, 1672-1678.

53 M. S. Ghazvini, G. Pulletikurthi, A. Lahiri and F. Endres, ChemElectroChem, 2016, 3, 598-604.

54 L. Oniciu and L. Mureşan, Journal of Applied Electrochemistry, 1991, 21, 565-574. 